\title{
ESTRELLAS RIOJANAS. GEOGLIFOS DEL NORTE DE LA PROVINCIA DE LA RIOJA, ARGENTINA
}

\author{
THE STARS OF LA RIOJA. GEOGLYPHS IN NORTHERN LA RIOJA PROVINCE, \\ ARGENTINA
}

Adriana Callegari, Gisela Spengler \& \& Silvia de Achac

En este trabajo se analiza un tipo particular de expresiones visuales prehispánicas del norte de La Rioja. Se trata de geoglifos o estructuras cubiertas con piedras de colores cuidadosamente seleccionadas. De acuerdo con los emplazamientos cercanos, el material cerámico superficial y los resultados de las mediciones radiocarbónicas, estas manifestaciones plástico-arquitectónicas habrían sido construidas y utilizadas durante el primer milenio AD. En el transcurso de este extenso lapso temporal sus características formales habrían ido cambiando en función de las variaciones en la performance del ritual, mientras que los colores seleccionados para producir un impacto visual se habrían mantenido a lo largo del tiempo.

Palabras clave: Norte de la Provincia de La Rioja, Geoglifos, Estructuras de Piedras de Colores, Marcadores Territoriales, Significación del Espacio.

This paper presents an analysis of a particular type of pre-Hispanic visual expression found in northern La Rioja-geoglyphs, or structures covered with carefully selected stones of different colors. According to nearby sites, ceramic material found on the surface, and the results of radiocarbon measurements, these artistic-architectural structures were built and used during the first millennium AD. Over that long timeframe, their formal use shifted as the rituals performed there varied, while the colors selected for their visual impact endured over time.

Keywords: Northern La Rioja Province, Geoglyphs, Colored Stone Structures, Territorial Markers, Signifiers of Space.

\section{INTRODUCCIÓN}

En este trabajo nos ocupamos de un grupo de expresiones plástico-arquitectónicas características del norte de la Provincia de La Rioja. De formas, diseños y dimensiones variadas, claramente se destacan en el paisaje significándolo y connotándolo de una particular identidad. En la mayoría de los casos presentan diseños estrellados conformados por la alternancia de piedras seleccionadas de colores blancuzco, negro-azulado y rojizo, que cubren la superficie de soportes terraplenados de tierra.

A la fecha hemos registrado un total de 29 estructuras de este tipo, distribuidas en 12 sitios ubicados en los valles de Vinchina y Antinaco. De acuerdo con las evidencias cronológicas relativas y a los resultados de las mediciones radiocarbónicas obtenidas en dos de ellas, estas manifestaciones parecen haber formado parte de una tradición que, con sucesivas resignificaciones, se habría extendido desde el Período Temprano (ca. 100 AC - 0-600 DC) hasta el Período Tardío (ca. 1000 DC 1350 DC). Con el fin de asomarnos a la significación de estas estructuras nos focalizaremos en los aspectos que

A Adriana Callegari. Instituto de Arqueología, Facultad de Filosofía y Letras, Universidad de Buenos Aires. 25 de Mayo 217, $3^{\text {er }}$ piso (CP1002), Buenos Aires. Email: acallega@gmail.com

B Gisela Spengler. Instituto de Arqueología, Facultad de Filosofía y Letras, Universidad de Buenos Aires - CONICET. 25 de Mayo 217 , $3^{\text {er }}$ piso (CP1002), Buenos Aires. Email: giselaspengler@gmail.com.

C Silvia de Acha. Instituto de Arqueología, Facultad de Filosofía y Letras, Universidad de Buenos Aires. 25 de Mayo 217, $3^{\text {er }}$ piso (CP1002), Buenos Aires. Email: sdeacha@gmail.com 
hacen al emplazamiento, a las técnicas de construcción, al diseño, a la elección de los colores y a los materiales arqueológicos que las rodean.

\section{DESARROLLO TEÓRICO}

Las poblaciones connotan los espacios de práctica tanto por componentes imaginarios como materiales. Entre los primeros, simplemente asignándoles una nominación o replicando un relato oral en relación con ellos a lo largo del tiempo. Mientras que entre los segundos, por la instalación de hitos en el paisaje con el objetivo de delimitar y significar ciertos lugares (Potter 2004) (v. g. manifestaciones de arte rupestre, construcción de monumentos, geoglifos, etc.). De esta manera, el paisaje puede ser entendido como el producto de una idea o percepción compartida por los miembros de una sociedad (Criado Boado 1999, Mañana Borrazás et al. 2002) y responde a diferentes esquemas de pensamiento y códigos de uso del espacio (Criado Boado 1999, Tilley 2008). Es el resultado de las representaciones producidas, significadas y resignificadas históricamente (Ingold 1993, 2000; Thomas 2001).

Las ideas y los preceptos de una cosmovisión consensuada se objetivan a través de diferentes modalidades que, con ciertas variaciones, dan cuenta de formas de expresión compartidas a lo largo de extensas regiones, constituyéndose con el correr del tiempo en tradiciones. Estos saberes y prácticas contribuyen a forjar la identidad de una sociedad y son aprendidos e incorporados a través de narrativas orales y la participación en rituales y ceremonias (Bradley 2002).

La "memoria materializada" se expresa en la materialidad de lo "memorizable", que es una manifestación de la memoria colectiva, cumpliendo así una función mnemotécnica (Kaulicke 2003). Este tipo de procesos suele relacionarse con los monumentos que se caracterizan por su permanencia, escala, centralidad y ubicuidad, entre otros atributos (Moore 1996). Es por esta razón que estos fueron erigidos para, desde su sola presencia, actuar sobre la memoria social con la intención de consagrar y perpetuar una particular visión del mundo a las futuras generaciones. No obstante, con el correr del tiempo y al proyectarse sobre ellos sucesivas resignificaciones, el contenido de su mensaje se va diluyendo, dando lugar a otras memorias (Barrett 1999, Thomas 2001, Bradley 2002). Las marcas dejadas en el paisaje trabajan sobre la memoria colectiva, constituyendo redes de significados a través del tiempo (Clarkson 1998). Este proceso de interacción entre los individuos y los objetos plantea relaciones complejas y dinámicas que favorecen la construcción de significados y la trasmisión de información de generación en generación, en relación con la identidad de quienes los construyen y utilizan. La memoria requiere de una objetivación en forma de símbolos para insertarse en un sistema de ideas compartidas. Estos símbolos son repetidos periódicamente en fiestas y ceremonias, convirtiéndose en tiempo vivido colectivamente al interior de un espacio que sirve de marco referencial. Este espacio también contempla el mundo de los objetos que ofrecen un entorno de permanencia y estabilidad (Kaulicke 2003).

En los objetos de arte las propiedades visuales tienen mayor relevancia que entre otros, pues fueron creados para ser vistos. Las propiedades de sus diseños, formas, colores y tamaños se orientan a producir una imagen que se destaca respecto de un fondo (Fiore 2011). Las imágenes plasmadas sobre variados soportes de representación definen el lenguaje visual de una sociedad en un tiempo-espacio determinado. Muestran características particulares en cuanto a la red de relaciones, preferencias estéticas y códigos de diseños compartidos por quienes participan de cierto entramado social. Además, cumplen un importante rol en la construcción de creencias y significados, como así también en los procesos de socialización, a través de los cuales se definen las formas de mirar y entender el mundo. Para encarar su estudio y llegar a interpretar de qué manera contribuyen a configurar lugares específicos en los que la gente vive y transita, es necesario definir los contextos de los que participan (Basile 2013: 187-188).

Aquellos lugares significantes, portadores de una alta carga simbólica y/o vinculados a acciones míticoreligiosas, son señalados con marcas que impactan en los sentidos, transformándolos de esta manera en focos de emoción. No solo las imágenes o figuras de los artefactos son portadoras de valores simbólicos, a menudo también los colores y los materiales de fabricación son usados para crear y recrear determinadas experiencias. El simbolismo puede verse fortalecido por el efecto que la percepción de algunos factores provoca como, por ejemplo, el color o un sonido, o de otras cualidades naturales o imaginarias de los materiales reconocidas por los productores y usuarios (Hosler 1998). Particularmente, el factor color depende de la existencia de luz y 
del objeto que la refleja, pero su percepción y cognición están en función del bagaje cultural del individuo que lo recibe y del contexto social de interacción. Es una de las vías por las que el mundo se incorpora sensiblemente a la experiencia humana y a través de ella a la práctica social. Siguiendo a Ávila (2011), consideramos que los colores suponen múltiples prácticas y encuentros con lo material, conformando una red social y de sentido que involucra a personas, objetos, acciones, gestos, momentos y lugares. En el marco del estudio del uso de los colores en expresiones plásticas ejecutadas sobre soportes cerámicos, esta autora comenta que "Nuestro punto de partida es analizar cómo se confeccionan ciertos conjuntos de objetos en patrones cromáticos reiterados, generando una unidad (perceptiva) que es prácticamente reconocida por un grupo de personas en un tiempo y en un espacio determinados. Buscamos identificar configuraciones particulares que producen efectos que se experimentan en formas compartidas, resultando en prácticas comunes" (Ávila 2011: 99).

En estrecha relación con los sentidos, el lenguaje visual permite percibir e interpretar los objetos que nos rodean y captar la idea que subyace detrás de un diseño. El diseño representa, comunica, expresa y manifiesta significado, por lo tanto, resulta significante. Ambos, significante y significado, integran el signo que es el que evoca en el cerebro la metáfora. Estos elementos juntos conforman lo que desde el punto de vista del lenguaje se conoce como estructura significante, o sea un conjunto de señales que dan a entender algo (López de Olivera 2012: 221).

Las manifestaciones visuales de la América precolombina, entre ellas los geoglifos sobre los que se centra este trabajo, sin duda tuvieron una intención estética. Sin embargo, esta no se habría agotado en sí misma, sino que además cumplió un importante rol social en relación con las prácticas que se desarrollaron en los lugares donde los geoglifos fueron construidos, despertando sentimientos de pertenencia e identidad entre aquellos que compartieron un mismo imaginario simbólico.

\section{GEOGLIFOS EN EL NOROESTE ARGENTINO}

Los geoglifos han sido definidos como imágenes de grandes dimensiones figuradas sobre el terreno $(v \cdot g$. laderas de cerros, colinas, barrancas de ríos y/o planicies) con una clara intencionalidad de que sean vistos a la distancia (Núñez 1976). Diversos autores han caracterizado las técnicas básicas de elaboración de este tipo de estructuras: a) en el caso de terrenos pedregosos, mediante la limpieza o despeje de las rocas, constituyendo líneas o superficies en negativo; b) a partir de la acumulación de pequeñas piedras de coloración más clara o más oscura que la superficie del terreno, resultando en la demarcación de formas a través del contraste con el fondo; y c) por medio de la combinación de ambas técnicas, extractivas y acumulativas (Núñez 1985, Briones \& Chacama 1987, Clarkson \& Briones 2001, Valenzuela \& Clarkson 2014, entre otros).

Manifestaciones de este tipo han sido ampliamente identificadas en la zona andina para tiempos prehispánicos. Destacan los abundantes casos registrados para el área surandina, especialmente en el norte de Chile, vinculados al tránsito y al caravaneo (Clarkson \& Briones 2001). Sin embargo, en el Noroeste Argentino (NOA) las evidencias de geoglifos son escasas. Al respecto, pueden mencionarse los reportados por Muscio (2006) en la puna salteña, entre las quebradas de Urco y Matancillas. Se trata de geoglifos confeccionados a partir de la adición de piedras blancas, que representan esquemáticamente a grupos de camélidos y sus crías. Por su parte, en la localidad de La Angostura, ubicada en el Valle Calchaquí (Provincia de Salta), Raffino y colaboradores (Raffino 1981, Raffino et al. 1982) describieron un pequeño cerro de $5 \mathrm{~m}$ de altura, cuya cima fue previamente aterrazada y sobre el cual se delimitó un círculo de $3 \mathrm{~m}$ de diámetro y $0,30 \mathrm{~m}$ de alto confeccionado con rocas rojas, grises y blancas. En su interior se observó la representación de una cruz de brazos asimétricos conformada por piedras blancas.

En el norte de la Provincia de San Juan, Prieto (1992) mencionó la presencia de geoglifos emplazados sobre la margen del río Jáchal que representan figuras antropomorfas y zoomorfas de gran tamaño (entre $9 \mathrm{y}$ $13 \mathrm{~m}$ de largo). Estas fueron construidas con piedras de colores blanco, rojo y negro, identificándose también en las inmediaciones promontorios de rocas y pequeñas circunferencias de 1,50 m de diámetro delimitadas por piedras de colores. Además, en el Parque Provincial Ischigualasto y su área de amortiguación, Guráieb y colaboradores (Guráieb et al. 2007) han reportado la existencia de estructuras circulares cercanas a cursos de agua, cubiertas con piedras de colores blanco y negro, de diámetros que oscilan entre 8 y $9 \mathrm{~m}$ y que no configuran 
diseño alguno. Además, han registrado abundante material lítico en superficie y algunos fragmentos cerámicos que, de acuerdo con sus características tecnológicas, podrían asimilarse a la cerámica Aguada. Las mediciones realizadas por termoluminiscencia sobre algunos de estos fragmentos arrojaron fechados correspondientes al inicio y final del Período Medio. Estructuras con rasgos similares también fueron reconocidas en la Quebrada de La Troya, en las inmediaciones de la actual localidad de Guandacol, en el sudoeste de la Provincia de La Rioja y a $10 \mathrm{~km}$ del límite con la Provincia de San Juan (Callegari \& Spengler 2010). A pesar del avanzado grado de deterioro, se identificaron pequeñas elevaciones cubiertas con piedras mayoritariamente de color blanco. En uno de los casos fue posible individualizar una estructura bastante bien conservada de aproximadamente $12 \mathrm{~m}$ de diámetro y 0,60 $\mathrm{m}$ de altura, no habiéndose recuperado ningún material arqueológico en superficie.

\section{LOS GEOGLIFOS RIOJANOS}

Los trabajos realizados en el noroeste de la Provincia de La Rioja han permitido relevar una totalidad de 29 geoglifos y estructuras de piedras de colores emplazados en ambientes de fondo de valle, distribuidos en 12 sitios ubicados en las localidades de Vinchina, Las Eras Viejas, Rueda de Piedra, Angulos, La Cuestecilla, Cerrito Negro y El Cantadero. Las tres primeras localidades se encuentran en el sector norte del Valle de Vinchina, mientras que las restantes se emplazan en el Valle de Antinaco. Es interesante señalar que entre ambos valles media una distancia de aproximadamente $95 \mathrm{~km}$ y se interpone la sierra de Famatina con picos que superan los $6000 \mathrm{msnm}$ (fig. 1).

Estas estructuras, de formas y diseños variados, fueron logradas mediantes diferentes técnicas constructivas. Una de ellas consistió en la construcción de plataformas circulares cuyos taludes fueron recubiertos por piedras de colores blancuzcos, rojizos y negro-azulados, conformando triángulos que por su alternancia figuran diseños de estrellas (fig. 2). La parte superior y central de estas estructuras de planta circular se encuentra levemente deprimida y despejada de rocas, siendo posible el acceso al espacio central a través de un corredor o pasillo que no fue cubierto por piedras.

Otra técnica consistió en la acumulación de tierra a manera de muros de morfología lineal, concéntrica o en espiral, cubiertos por piedras de las tonalidades mencionadas. Por último, también se registraron algunos casos en los cuales se elevaron pequeños montículos de tierra tapizados en su totalidad con piedras de colores seleccionadas.

En el Valle de Vinchina se pudo determinar que las materias primas utilizadas en la construcción de estas estructuras son locales y corresponden a rodados de río que abundan en la zona, especialmente en los lechos secos de cauces estacionales. En el caso de las rocas de color rojizo se identificó el uso de areniscas con alto contenido de hierro. Por su parte, para las rocas de tonalidad blanquecina se observó la presencia de cuarzos y rocas graníticas. Finalmente, los materiales de color negro/azulado corresponden a rocas de origen diverso, como volcanitas, esquistos y areniscas que, en todos los casos, presentan pátina o barniz del desierto.

\section{VALLE DE VINCHINA}

\section{Estrellas de Vinchina}

En el sector septentrional del Valle de Vinchina, en las inmediaciones de la localidad homónima, se emplaza un conjunto de estructuras de piedras de colores (fig. 3). De la Fuente (1973) fue el primero en llamar la atención sobre este tipo de expresiones plásticas a las que consideró geoglifos y denominó como "estrellas", atendiendo al diseño en picos que presentaban y siguiendo el decir de los lugareños. Se trata de siete estructuras circulares de diferentes diámetros, ubicadas a $28^{\circ} 44^{\prime} 42,2^{\prime \prime}$ latitud sur y $68^{\circ} 13^{\prime} 26,1^{\prime \prime}$ longitud oeste. Se emplazan sobre la margen occidental del río Vinchina, a aproximadamente $200 \mathrm{~m}$ de su cauce, y se distribuyen siguiendo una alineación relativa noroeste-sudeste y norte-sur. Esta distribución parecería orientarse hacia la Quebrada de la Troya, paso natural que conduce hacia la puna riojana y a Chile a través de los pasos cordilleranos de Comecaballos y Piedras Negras.

Cuando visitamos el sitio por primera vez en 1982 aún era posible distinguir las siete estrellas, aunque la del extremo sur (E7) ya se encontraba atravesada por una torrentera (Callegari \& Raviña 2000). La parte superior de todas ellas se encontraba levemente deprimida presentando en el centro un pequeño círculo de piedras marrones al que se accede a través de un estrecho corredor. Las piedras que delimitaban estas pequeñas circunferencias provenían del cerro Morado ubicado 


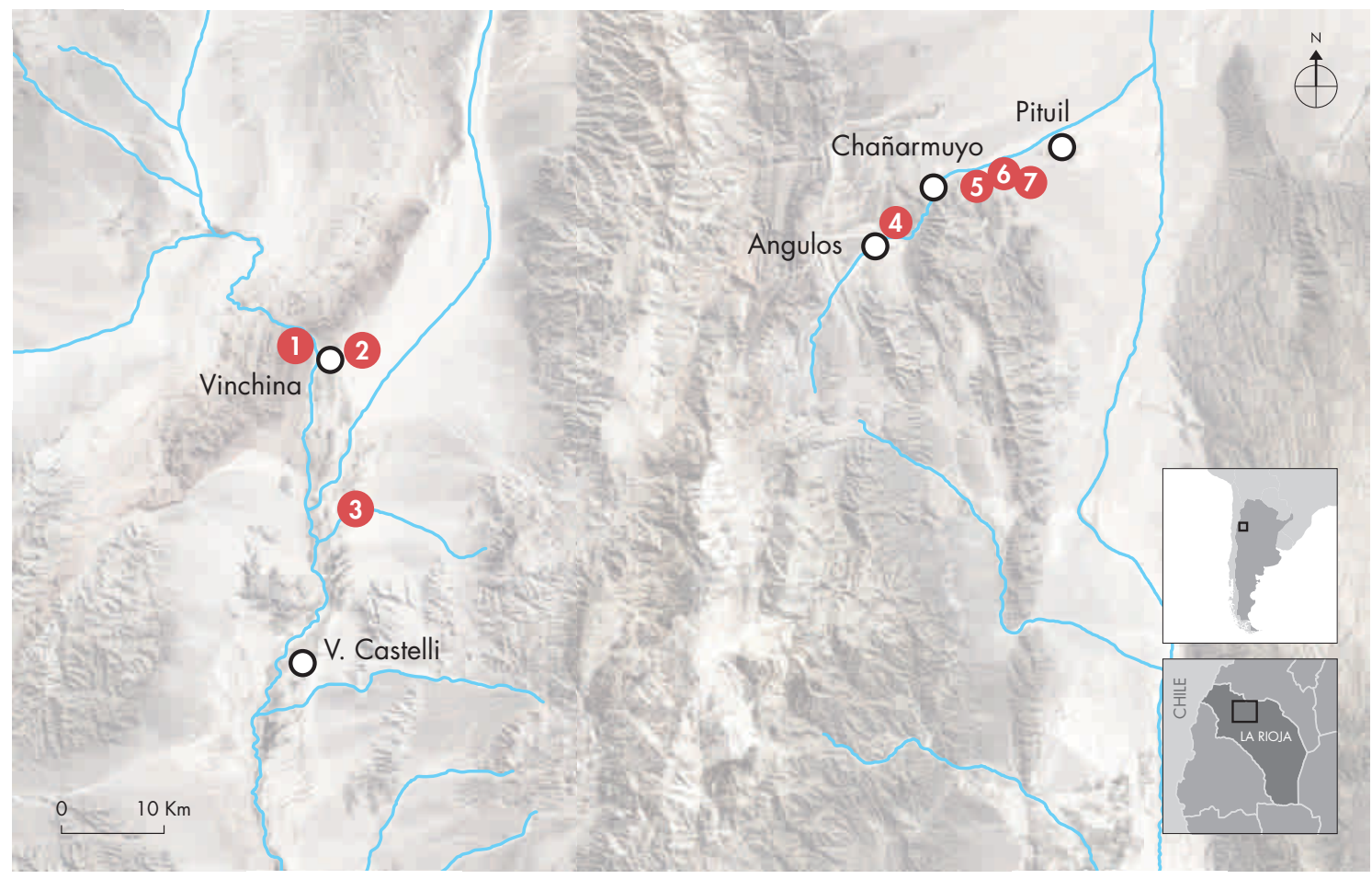

Figura 1. Ubicación de las localidades del noroeste riojano que presentan estructuras de piedras de colores: 1) Estrellas de Vinchina; 2) Las Eras Viejas; 3) Rueda de Piedra; 4) Angulos; 5) La Cuestecilla; 6) Cerrito Negro y 7) El Cantadero. Figure 1. Location of the sites with colored stone structures in northwest La Rioja province: 1) Estrellas de Vinchina; 2) Las Eras Viejas; 3) Rueda de Piedra; 4) Angulos; 5) La Cuestecilla; 6) Cerrito Negro and 7) El Cantadero.

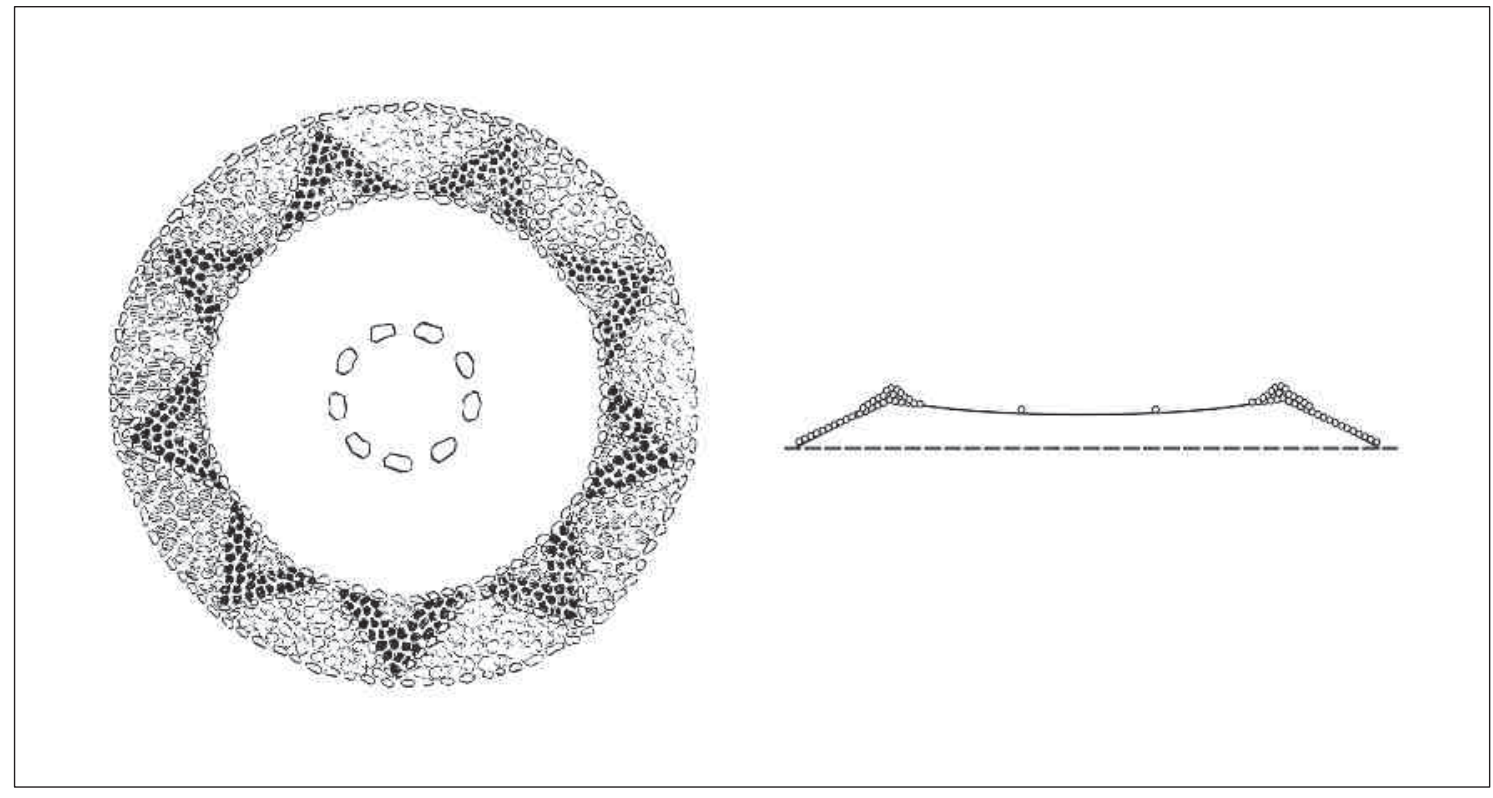

Figura 2. Esquema de planta y perfil de una estructura de piedras de colores con diseño de estrella (modificado de De la Fuente 1973: 104 y 107). Figure 2. Floor plan and profile of a colored stone structure with star design (modified from De la Fuente 1973: 104 and 107). 


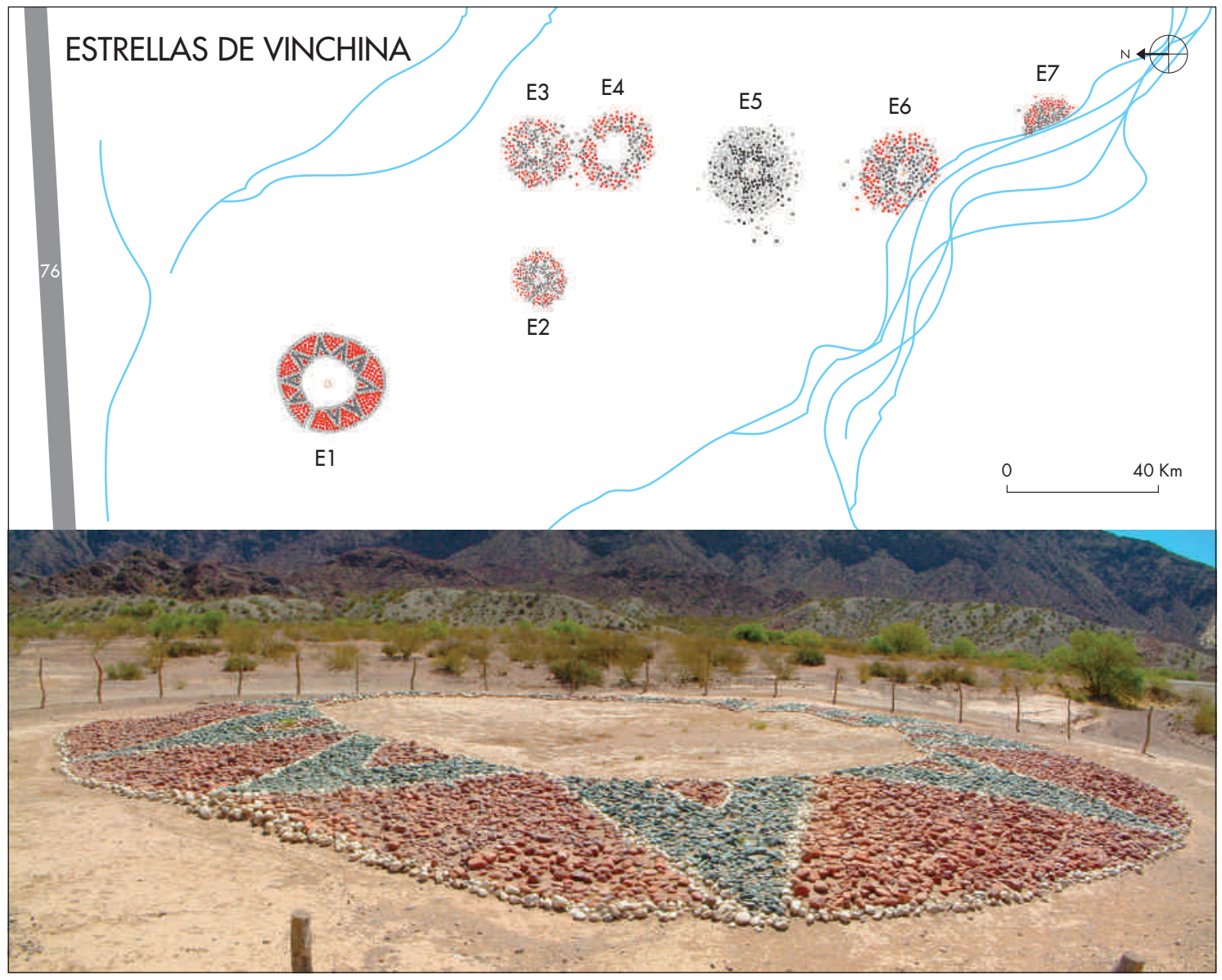

Figura 3. Plano de las Estrellas de Vinchina y fotografía de la estructura E1. Figure 3. Plan of Estrellas de Vinchina site and photo of structure E1.

en las cercanías. Al interior del pequeño círculo de E1 las intervenciones de De la Fuente (1973) permitieron recuperar fragmentos de una vasija Ciénaga II (transición Aguada) y cerámica Aguada, junto con abundantes fragmentos correspondientes a los estilos Belén y Sanagasta en las inmediaciones. Por su parte, nuestros trabajos de recolección superficial permitieron recuperar gran cantidad de material cerámico $(\mathrm{N}=328)$, cuyos resultados son los siguientes: Aguada 50\%, Inclusiones Finas 28\%, Sanagasta $14 \%$ y Ordinaria $8 \%$.

Es importante mencionar que años más tarde el sitio fue objeto de importantes alteraciones antrópicas que involucraron la construcción de un polígono de tiro en el área y destruyeron gran parte de las estructuras, conservándose en la actualidad solamente la estructura 1 (E1) que fue restaurada en los años setenta. Con posterioridad se replicaron dos estructuras más pequeñas
(E2 y E3), pero sin respetar los emplazamientos, la morfología ni la alternancia de los colores originales.

Ahora bien, ubicada en el extremo norte del sitio, E1 corresponde a la estructura de mayores dimensiones, con un diámetro exterior de aproximadamente $26 \mathrm{~m}$, uno interior de $11 \mathrm{~m}$ y un terraplén de ca. 0,50 $\mathrm{m}$ de altura. Por su parte, originalmente la estructura más pequeña (E2) presentaba un diámetro exterior de $15 \mathrm{~m}$ y uno interior de $4 \mathrm{~m}$. En cuanto a la configuración del diseño, seis de los siete geoglifos presentaban la superficie del talud cubierta con triángulos de rocas negras delimitados por blancas, sobre un fondo revestido de piedras rojas. En el caso de E1, los triángulos que conforman los picos presentan una hipotenusa de alrededor de 10 m. La excepción con respecto al uso de los colores la constituye $\mathrm{E} 5^{1}$ que fue confeccionada con triángulos rellenos con piedras negro-azuladas sobre un fondo de 


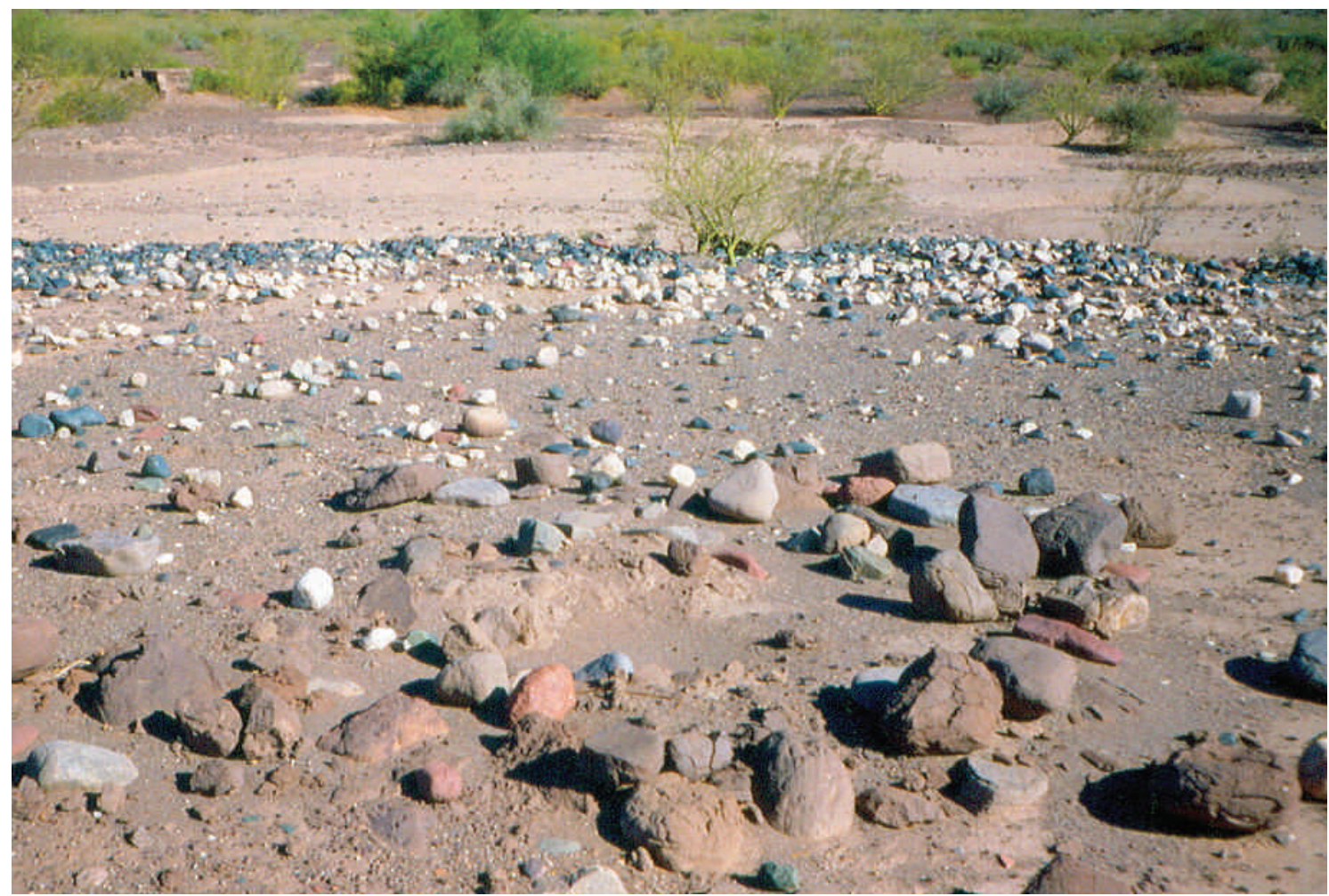

Figura 4. Detalle de la estructura E5 de las Estrellas de Vinchina. Se observa la combinación de rocas blancas y negro-azuladas en el exterior y la presencia de un círculo central de piedras marrones (fotografía de 1982). Figure 4. Detail of structure E5 at Estrellas de Vinchina, showing the combination of white and blackish-blue rocks on the periphery and a central ring of reddish-brown stones (photo from 1982).

rocas blancas (fig. 4). Por último, es de destacar que en cuatro de estas construcciones fue posible individualizar un pasillo al interior levemente deprimido, cuyo acceso en E3 y E5 se orientaba hacia el sudeste, en E1 hacia el noroeste y en E4 hacia el noreste.

\section{Las Eras Viejas}

El extenso barrial de Las Eras Viejas (Ev) cubre una superficie de aproximadamente $13 \mathrm{~km}^{2}$ hacia el este de la localidad de Vinchina y se extiende a lo largo de la margen oriental del río homónimo con dirección sudoeste-noreste. Sobre esta vasta planicie denudada por los agentes erosivos, individualizamos varias estructuras de piedras de colores distribuidas en cinco sitios, entre los cuales median distancias de 0,5 a $2,5 \mathrm{~km}$. En cuatro casos, EV2, EV3, EV4 y EV19 se identificó una única estructura, mientras que en EV18 se registraron varias de estas construcciones de diferentes formas y dimensiones. En todos estos sitios se recolectó gran cantidad de material cerámico y lítico en superficie, destacándose en algunos casos este último por su abundancia.

EV2: El sitio se ubica a $28^{\circ} 48^{\prime} 9,70^{\prime \prime}$ latitud sur y $68^{\circ} 10^{\prime}$ $04,90^{\prime \prime}$ longitud oeste. Está compuesto por una estructura terraplenada de forma circular de aproximadamente 11 $\mathrm{m}$ de diámetro que se encuentra cubierta con piedras negras, rojas y blancas, cuya alternancia pareciera figurar un diseño de estrella. Presenta dos posibles aberturas no cubiertas con piedras, orientadas una al norte y la otra hacia el este, que dan acceso a la parte central algo deprimida (fig. 5). Circundando la estructura se observan pequeñas elevaciones de tierra de diferentes formas que también fueron cubiertas por piedras de colores. En las inmediaciones hay abundante cantidad de material cerámico y lítico, que va disminuyendo notoriamente a medida que nos alejamos del sitio. Los estilos cerámicos identificados $(\mathrm{N}=79)$ son Aguada (67,09\%), Inclusiones Finas (18,99\%), Ordinarios (8,86\%) y Sanagasta (5,06\%). La clasificación del material lítico 


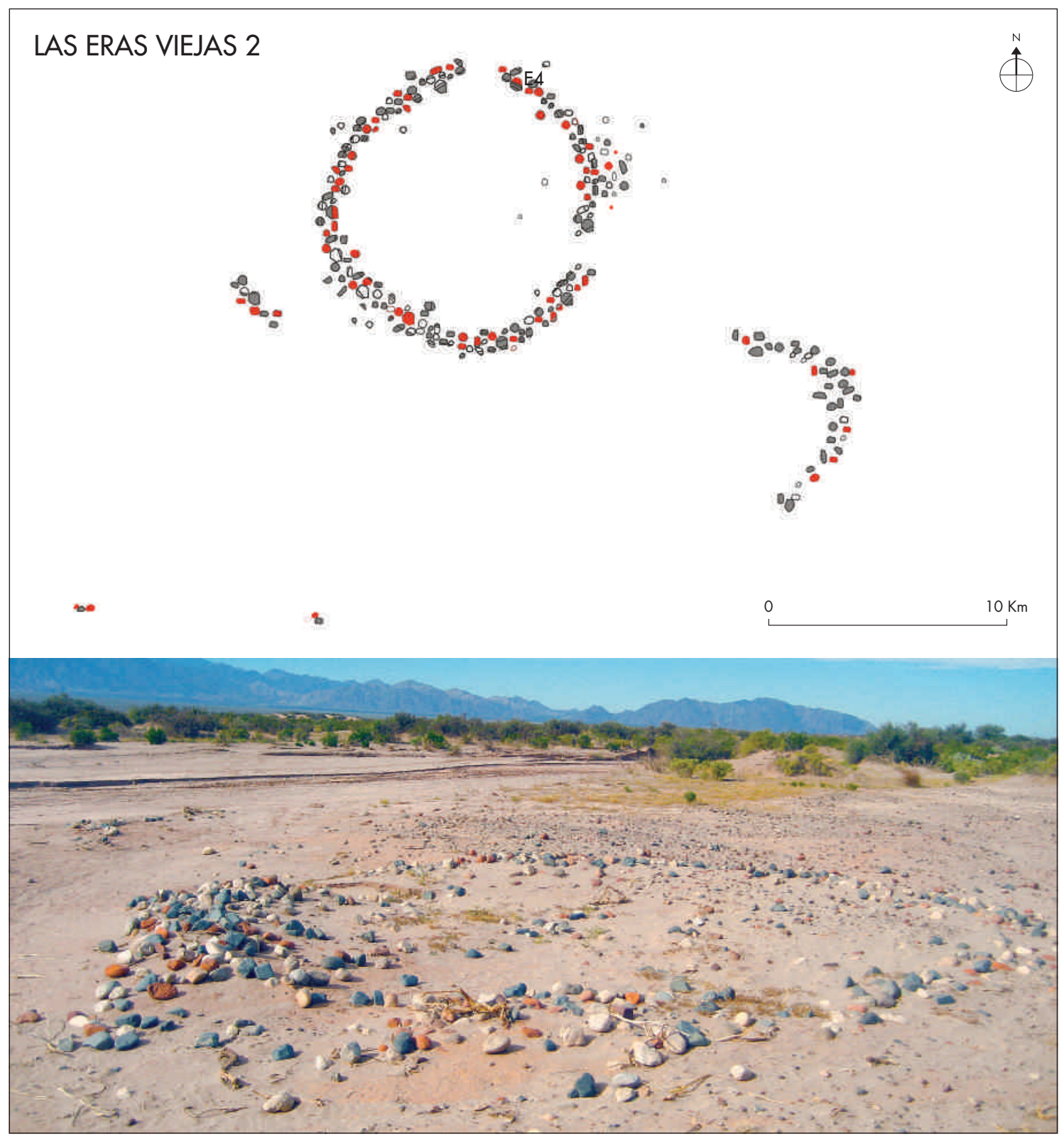

Figura 5. Plano y fotografía de la estructura de EV2. Figure 5. Plan and photo of structure EV2.

recolectado $(\mathrm{N}=24)$ dio como resultado la identificación de artefactos formatizados (8,33\%), consistentes en una punta burilante y una muesca retocada, filos naturales con rastros complementarios (25\%) y desechos $(66,67 \%)$.

EV3: Se emplaza a $28^{\circ} 46^{\prime} 41,10^{\prime \prime}$ latitud sur y $68^{\circ} 10^{\prime}$ $31,20^{\prime \prime}$ longitud oeste, está constituido por una única estructura de un diámetro que oscila entre los $10 \mathrm{y}$
$11 \mathrm{~m}$, donde se hace evidente la intencionalidad en la selección de los colores de las rocas (fig. 6). Se observa la presencia de un acceso al interior cuya abertura se orienta hacia el norte. En las inmediaciones hay abundante cantidad de material cerámico y lítico en superficie. Los estilos cerámicos identificados $(\mathrm{N}=168)$ son Ordinarios (46,43\%), Aguada (41,07\%), Inclusiones Finas (10,71\%) y Sanagasta (1,79\%). Por su parte el material lítico re- 


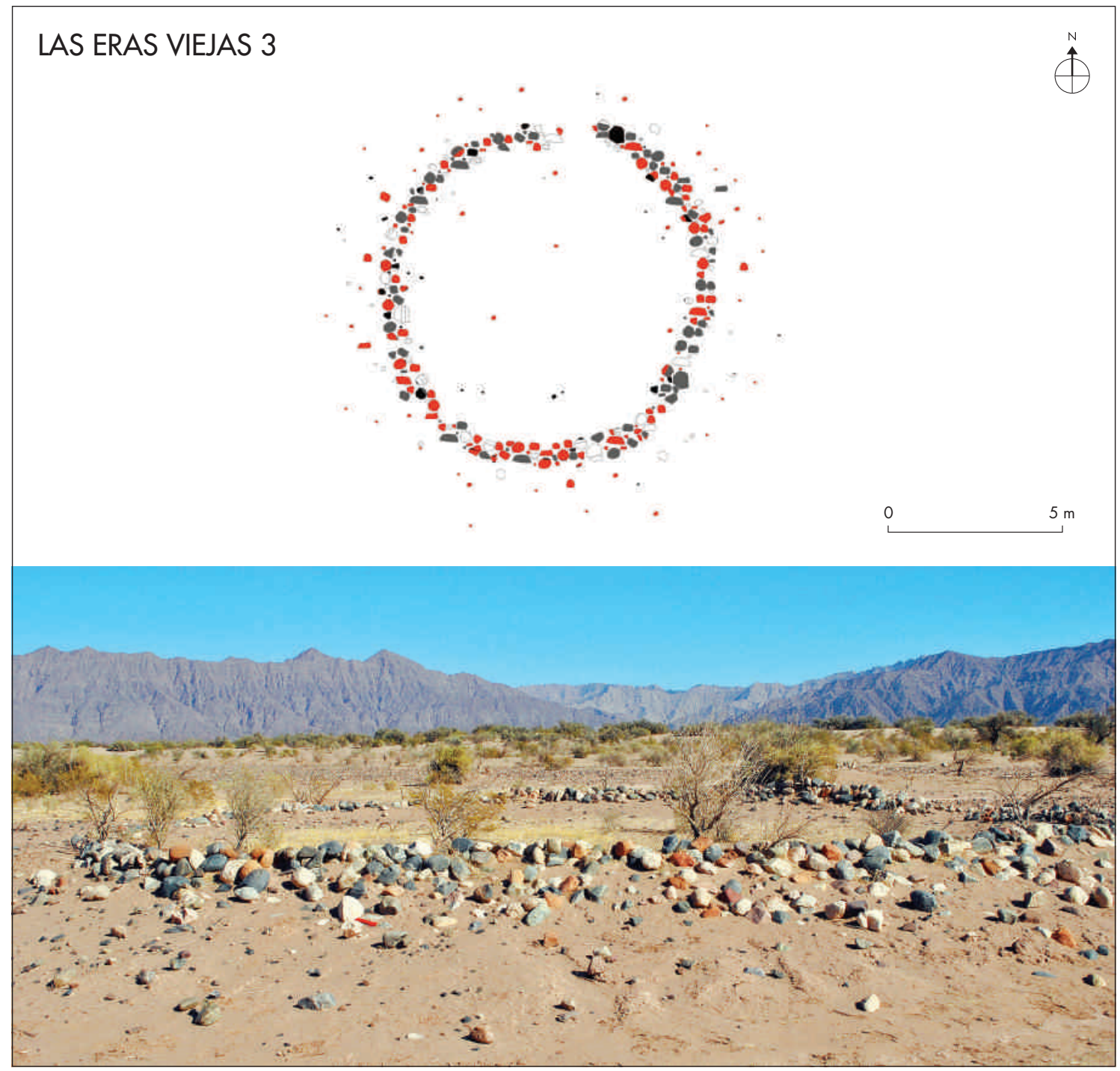

Figura 6. Plano y fotografía de la estructura de EV3. Figure 6. Plan and photo of structure EV3.

cuperado ( $\mathrm{N}=154)$ está conformado por filos naturales con rastros complementarios (12,99\%), artefactos formatizados $(5,84 \%)$, entre los que se encuentran un bifaz, dos raclettes, una punta entre muescas, dos artefactos de formatización sumaria y tres artefactos multifunción (denticulados, raederas, puntas burilantes y puntas entre muescas), núcleos (5,84\%), artefactos no formatizados con rastros complementarios $(0,65 \%)$ y desechos $(74,68 \%)$.

Se realizaron cateos en diferentes áreas del sector central de esta estructura, apareciendo en todos ellos pequeños fragmentos de carbón, cenizas y tierra quemada. También se abrió un sondeo de $1 \mathrm{~m}^{2}$ en la parte central, notándose en los primeros $10 \mathrm{~cm}$ un sedimento de tipo arenoso y muy friable con pequeños fragmentos de carbón. Entre los 10 y los $20 \mathrm{~cm}$ de profundidad se tornó más compacto, lo que dificultó su remoción y disminuyó la cantidad de carbón (Callegari \& Raviña 1982). Una de las muestras recuperadas fue fechada con el método de $\mathrm{C}^{14}$ (LP 2793) arrojando una antigüedad de $2060 \pm 80 \mathrm{AP}$, que calibrado con 1 sigma la ubican entre $112 \mathrm{AC}$ y $80 \mathrm{AD}$. En este sondeo se obtuvo un total de 28 fragmentos cerámicos, los cuales corresponden al tipo cerámico Aguada (50\%), Ordinarios (39,29\%) e Inclusiones Finas (10,71\%). Además, se recuperaron 


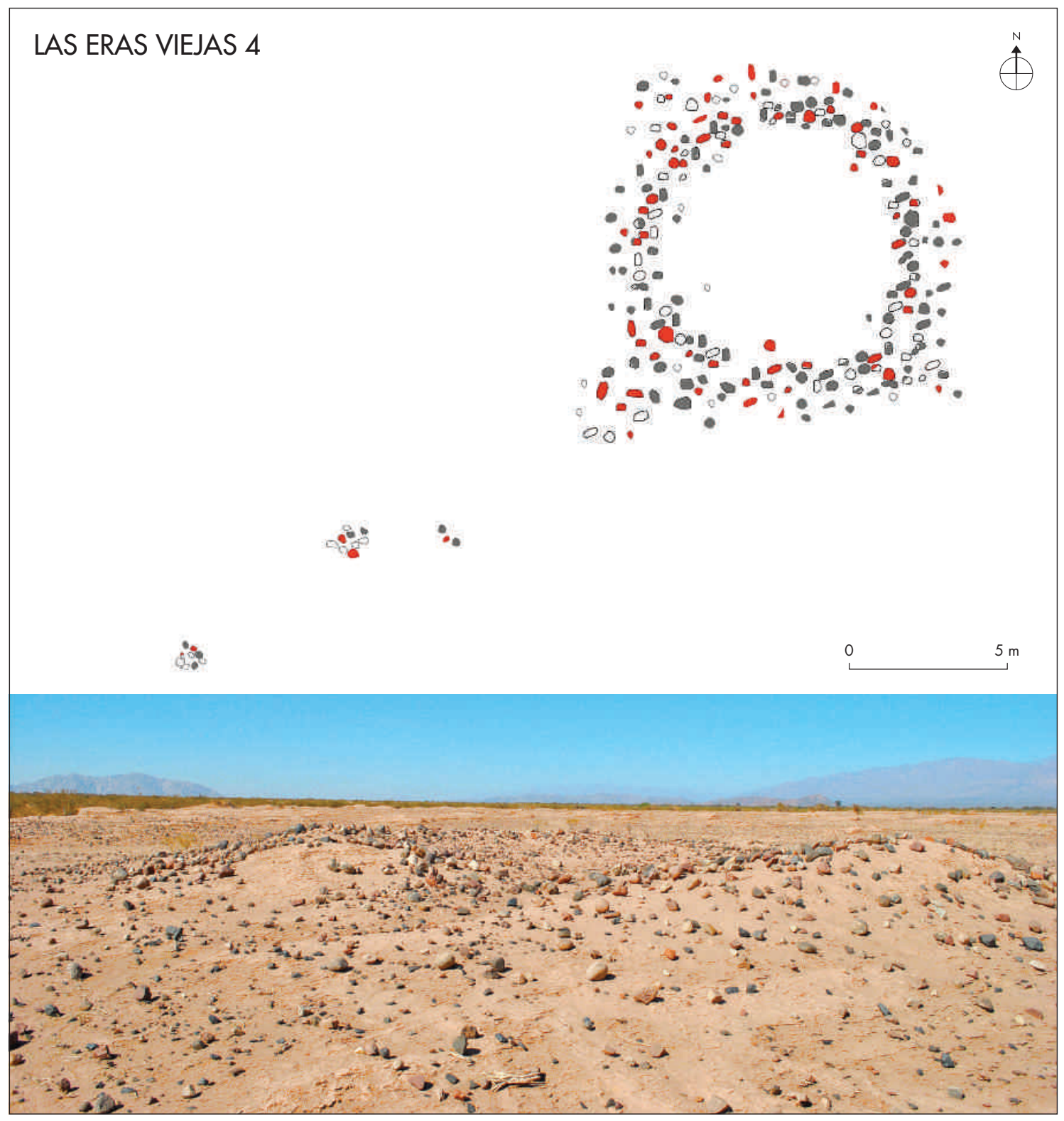

Figura 7. Plano y fotografía de la estructura de EV4. Figure 7. Plan and photo of structure EV4.

artefactos líticos $(\mathrm{N}=38)$ que fueron clasificados como núcleos $(2,63 \%)$ y desechos de talla $(97,37 \%)$.

EV4: Se ubica a $28^{\circ} 46^{\prime} 46,41^{\prime \prime}$ latitud sur y $68^{\circ} 10^{\prime} 18,49^{\prime \prime}$ longitud oeste y está conformado por una estructura relativamente erosionada, de aproximadamente $10 \mathrm{~m}$ de diámetro en la que aún es posible distinguir cierta intencionalidad en la distribución de las piedras de colores (fig. 7). También aquí se realizó una recolección de material cerámico de superficie $(\mathrm{N}=34)$ habiéndose identificado los estilos Aguada (61,76\%), Inclusiones Finas $(20,59 \%)$ y Ordinarios (17,65\%). Asimismo, se recolectó material lítico $(\mathrm{N}=20)$ que fue clasificado como filos naturales con rastros complementarios (25\%), artefactos formatizados (20\%), entre los que se encuentran un denticulado, una raedera, un artefacto de formatización sumaria y un artefacto compuesto (denticulado y muesca) y desechos (55\%). 


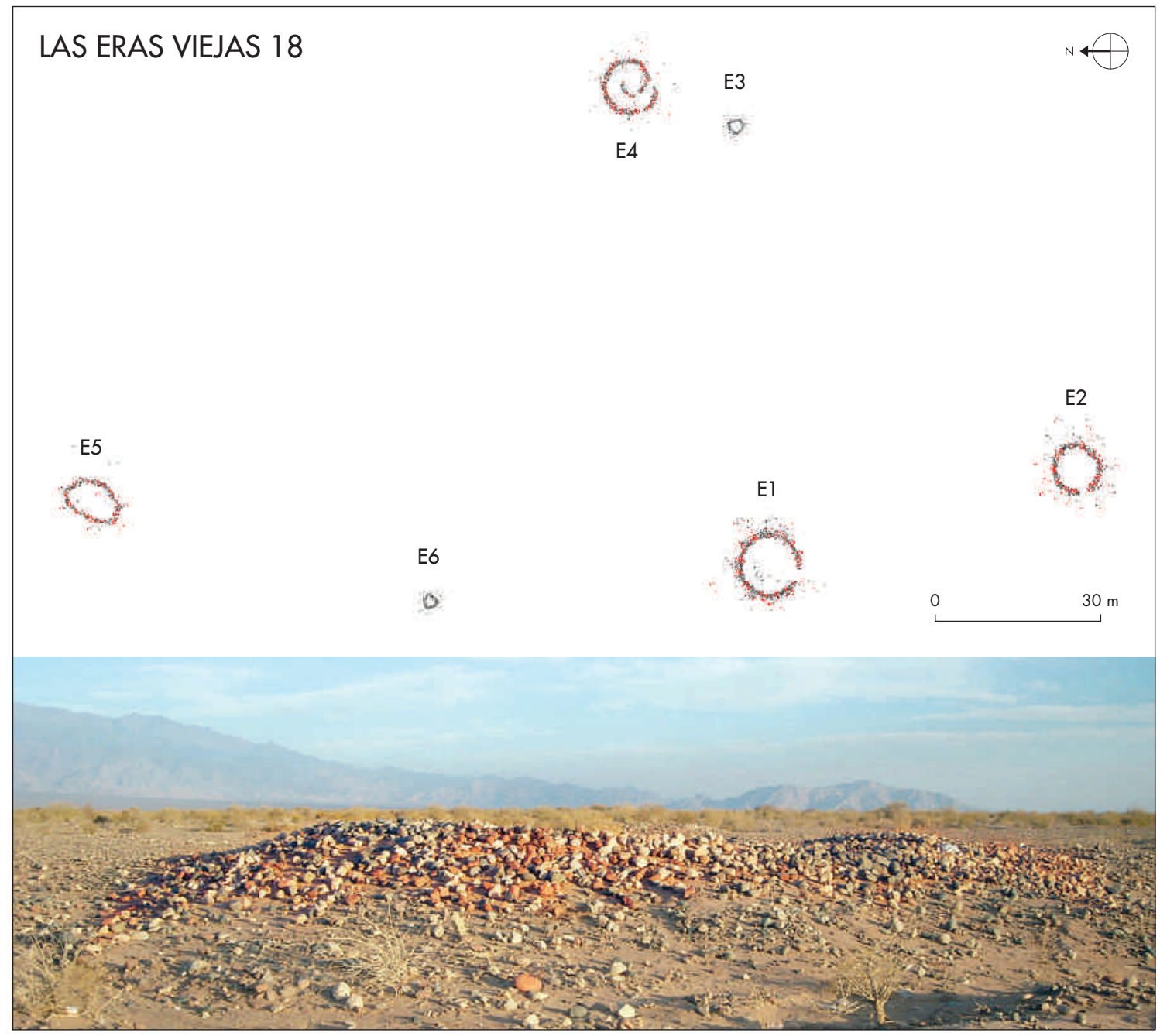

Figura 8. Plano de EV18 y fotografía de la estructura E1. Figure 8. Plan of EV18 and photo of structure E1.

EV18: Se emplaza a $28^{\circ} 46^{\prime} 22,49^{\prime \prime}$ latitud sur y $68^{\circ} 10^{\prime}$ $56,75^{\prime \prime}$ longitud oeste. A diferencia de los otros casos, este sitio está integrado por seis estructuras (fig. 8), entre las cuales se destacan cuatro sobreelevadas y cubiertas con piedras de colores (E1, E2, E4 y E5). Las dos restantes (E3 y E6), de pequeñas dimensiones, fueron construidas al ras del piso y no evidencian intencionalidad en la selección de los colores de las rocas.

Las estructuras E1 y E2 muestran diámetros que oscilan entre 10 y $11 \mathrm{~m}$, destacan por su altura y estado de conservación y presentan accesos con aberturas orientadas hacia el sudeste y oeste, respectivamente. En ambos casos, a la distancia aún es posible distinguir los picos triangulares que conformaban los diseños en estrella, por la alternancia en la aplicación de los colores de las piedras sobre el terraplén. La estructura E4 tiene un diámetro aproximado de $10 \mathrm{~m}$, se encuentra poco sobreelevada y presenta un diseño en forma de espiral, con un acceso que se abre en dirección sudeste. Por su parte, E5 está muy deteriorada pues fue atravesada por una cárcava, desplazándose hacia su interior parte de las piedras de colores que la cubrían y, probablemente, debido a esto, en la actualidad muestra una forma ovalada con diámetros aproximados de $11 \mathrm{~m}$ y $6 \mathrm{~m}$.

Es importante mencionar que estos geoglifos (E1, E2, E4 y E5) se diferencian claramente por su tamaño y características formales de las estructuras circulares más pequeñas, de tres metros aproximados de diámetro 


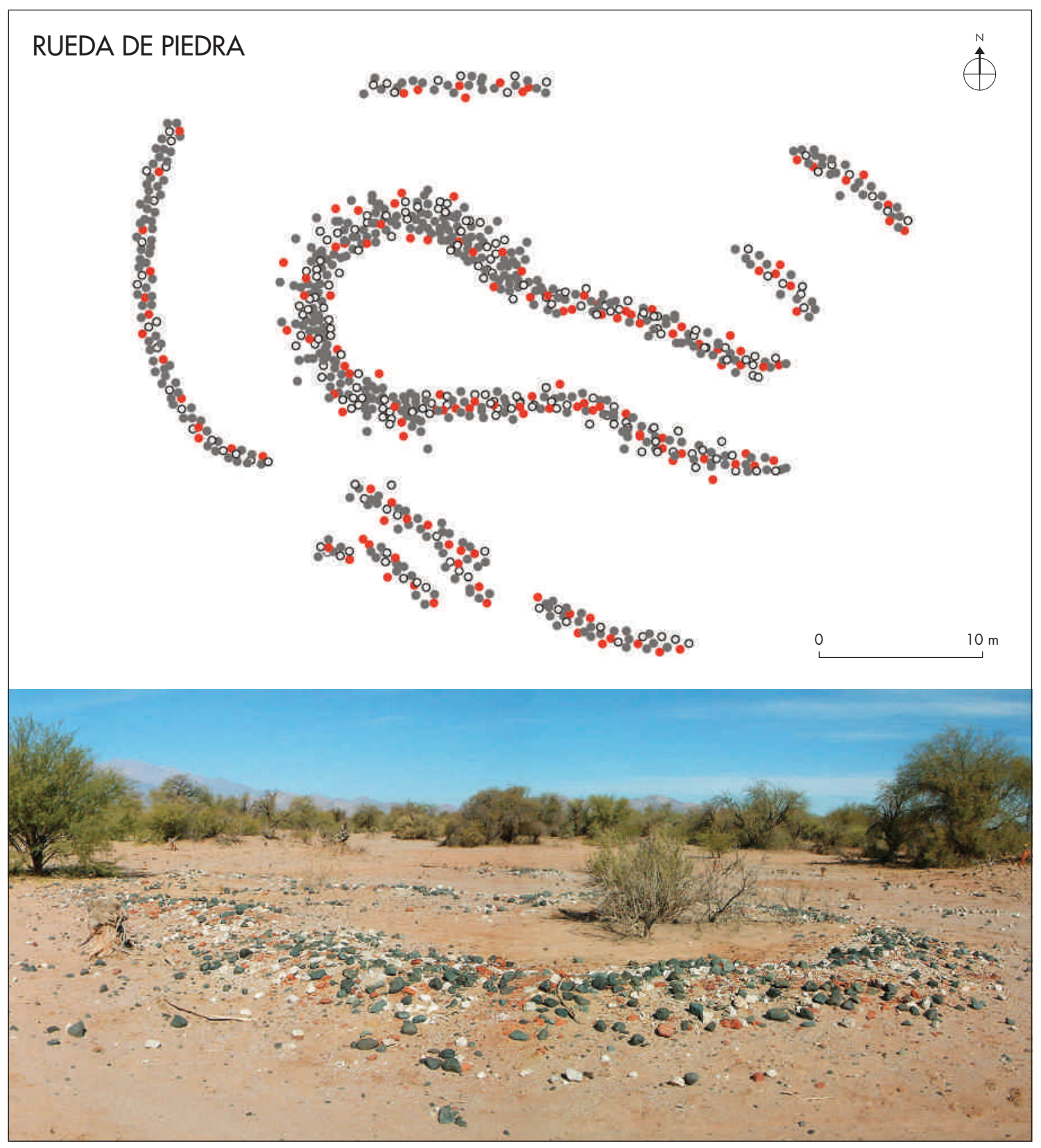

Figura 9. Plano y fotografía de la estructura de Rueda de Piedra. Figure 9. Plan and photo of the Wheel of Stone structure.

(E3 y E6). En estas últimas no se aplicó la estrategia del uso del color ya que fueron construidas con rocas de tonalidades marrón-grisáceas, motivo por el cual no han sido contabilizadas a los fines de este trabajo.

En diferentes sectores de la superficie central de E1, E2 y E4 se realizaron cateos en los que se registró la presencia de cantidad de espículas y pequeños frag- mentos de carbón a escasos centímetros de la superficie, alcanzando una profundidad de aproximadamente 0,20 $\mathrm{m}$. Se tomaron muestras en E4 para realizar fechados $\mathrm{C}^{14}$ (LP 2814), arrojando una antigüedad de $1750 \pm 60$ AP, que calibrado con 1 sigma lo ubican entre 316 y 415 AD. De forma similar a lo observado en EV3, con el que media una distancia de ca. $1 \mathrm{~km}$, los cateos realizados 


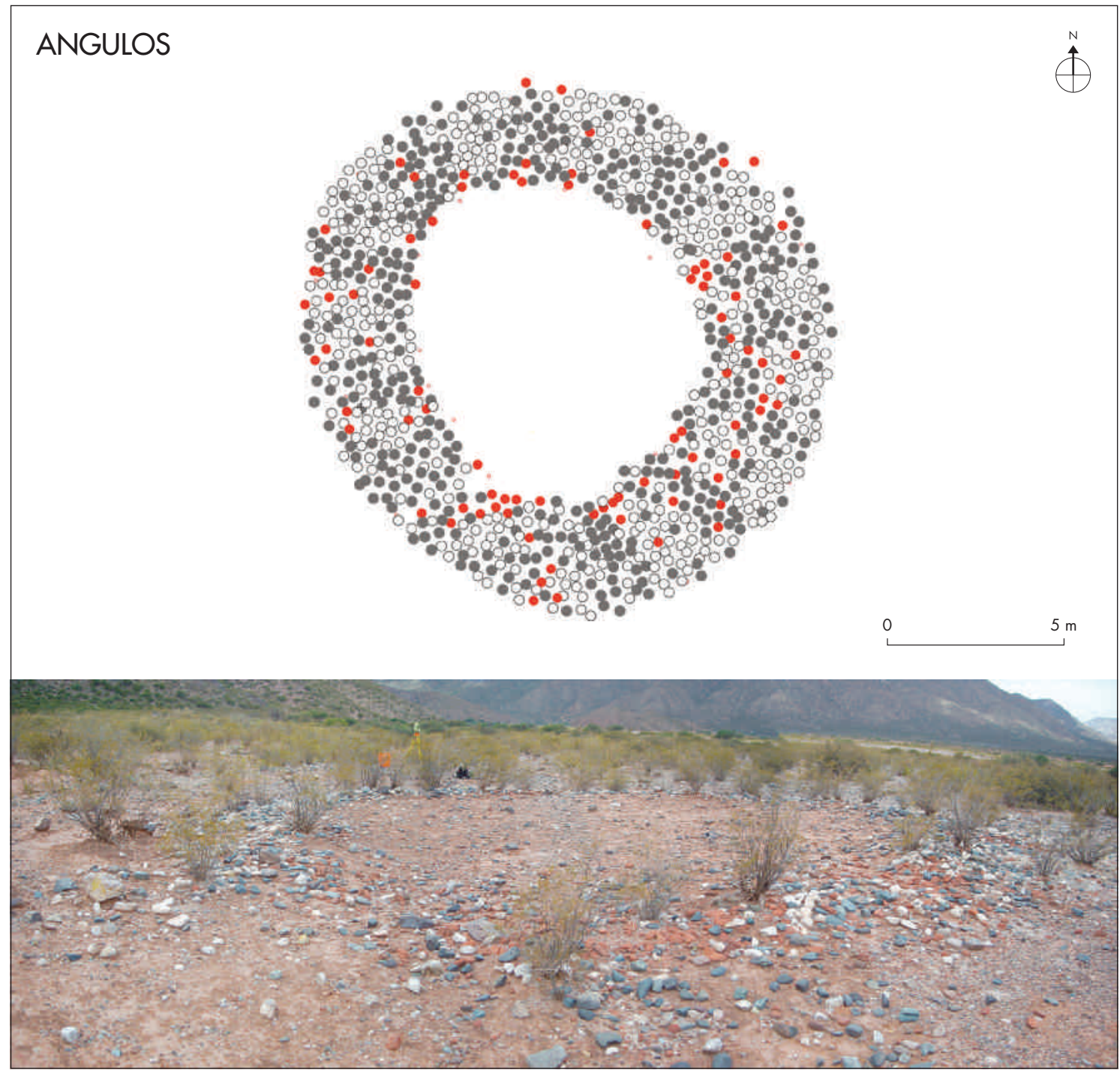

Figura 10. Plano y fotografía de la estructura de Angulos. Figure 10. Plan and photo of the Angles structure.

en las estructuras de EV18 mostraron inicialmente un sedimento suelto que a partir de los $0,25 \mathrm{~m}$ de profundidad se transformó en una arcilla muy compacta de difícil remoción, sin evidencias de actividades culturales.

En el sector donde se emplazan todas estas estructuras se individualizó una agrupación de ocho hornos circulares para cocer cerámica cuyos diámetros oscilan entre 0,63 y $0,85 \mathrm{~m}$. Además, es tal la abundancia de artefactos líticos en superficie que llega a invisibilizar al material cerámico, que no es escaso. Entre los fragmentos cerámicos colectados $(\mathrm{N}=136)$ se distinguieron los estilos Aguada (39,71\%), Ordinarios (39,71\%),
Sanagasta $(11,76 \%)$ e Inclusiones Finas $(8,82 \%)$. En cuanto al material lítico ( $\mathrm{N}=377)$, se identificaron desechos (83,29\%), artefactos formatizados $(7,16 \%)$, filos naturales con rastros complementarios $(6,9 \%)$ y núcleos (2,66\%). Los instrumentos reconocidos son cepillos, raederas, perforadores, denticulados, muescas, raspadores, puntas burilantes, artefactos con bisel oblicuo, artefactos de formatización sumaria y una variedad de artefactos multifunción.

EV19: En este sitio registramos una única estructura circular emplazada a $28^{\circ} 46^{\prime} 26,85^{\prime \prime}$ latitud sur y $68^{\circ}$ 


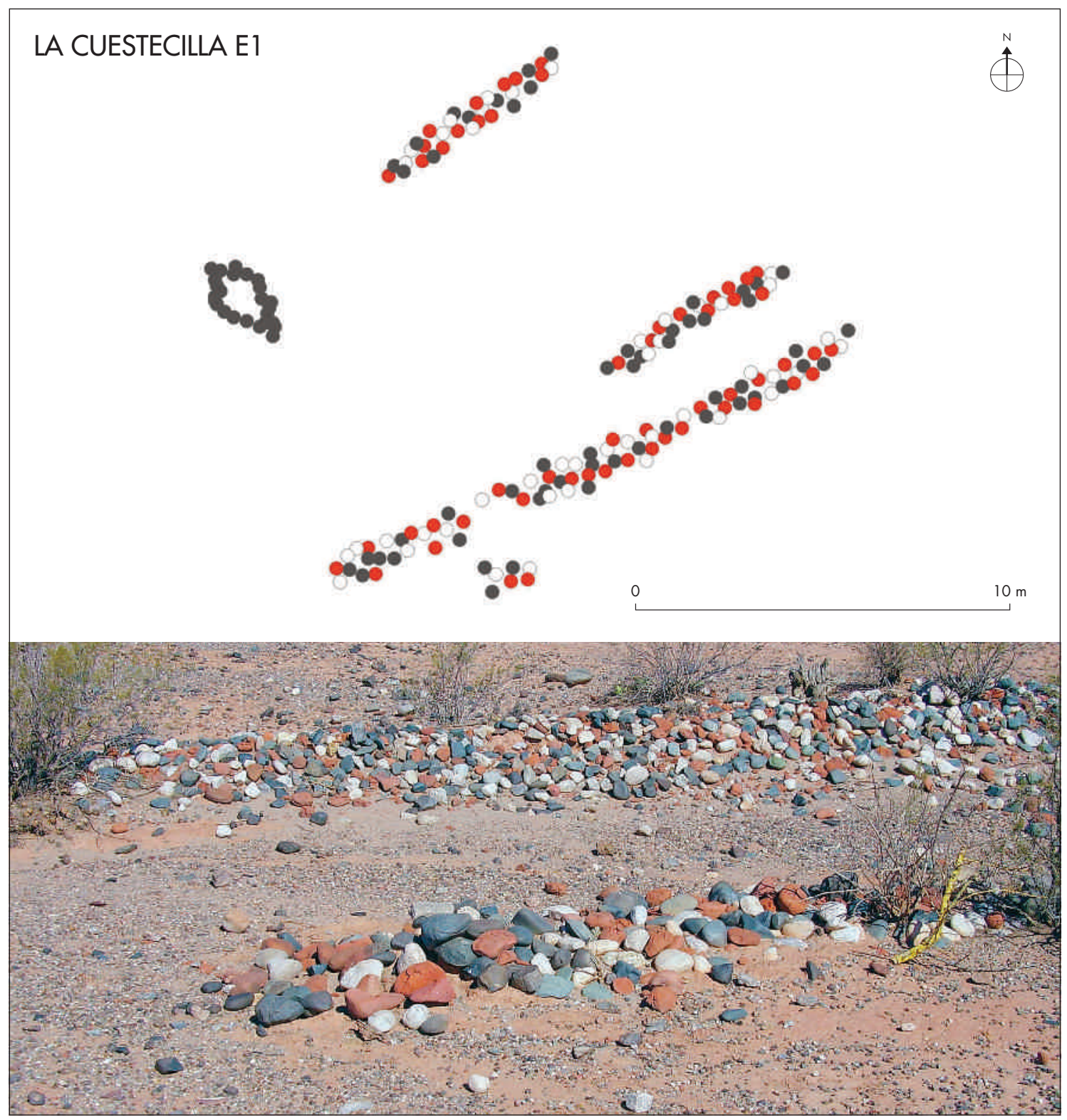

Figura 11. Plano y fotografía de la estructura E1 de La Cuestecilla. Figure 11. Plan and photo of structure E1 of La Cuestecilla.

10'28,93" longitud oeste. Si bien la misma se encuentra muy afectada por la erosión, aún es posible reconocer la intencionalidad en la selección de los colores que la cubren. Su diámetro fue estimado en aproximadamente $10 \mathrm{~m}$, registrándose un posible acceso al interior cuya abertura se orienta al noroeste. También en este caso es llamativa la gran cantidad de material lítico circundante y la menor proporción de fragmentos cerámicos. Realizado un muestreo sistemático y concluido el análisis de los tiestos (N=33), se obtuvo la siguiente clasificación: Ordinarios (84,85\%), Aguada (6,06\%), indeterminados (6,06\%) e Inclusiones Finas (3,03\%). Entre el material lítico recolectado $(N=65)$ se identificaron desechos $(81,54 \%)$, artefactos formatizados $(9,23 \%)$ consistentes en un cepillo, una punta burilante, un artefacto con retoque bisel oblicuo y tres instrumentos multifunción, filos naturales con rastros complementarios $(4,62 \%)$ y núcleos $(4,62 \%)$. 


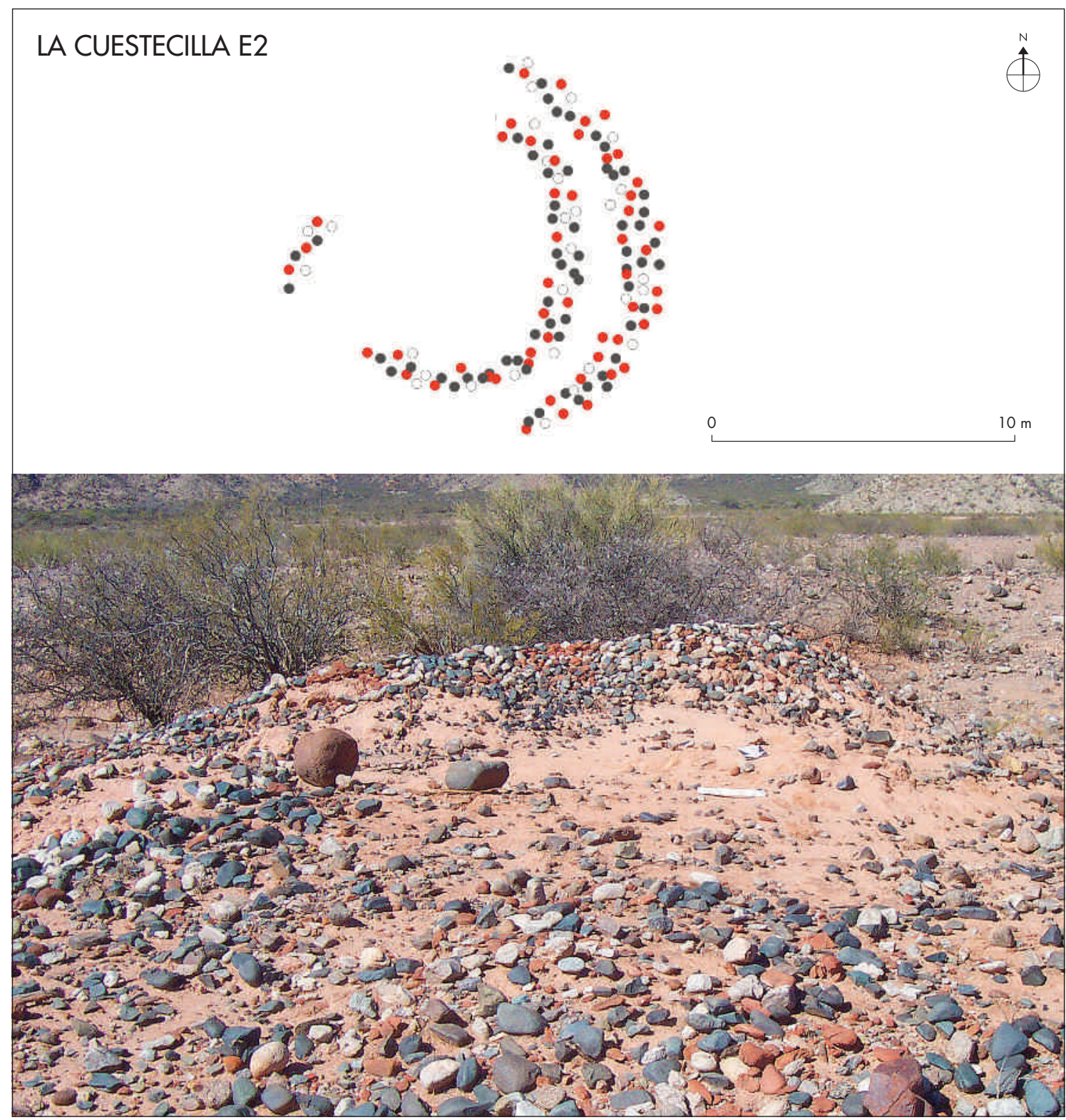

Figura 12. Plano y fotografía de la estructura E2 de La Cuestecilla. Figure 12. Plan and photo of structure E2 at La Cuestecilla.

\section{Rueda de Piedra}

Aproximadamente a $10 \mathrm{~km}$ hacia el sur de Las Eras Viejas y dentro de la finca El Galfón se individualizó un gran geoglifo muy bien conservado, denominado por los lugareños como Rueda de Piedra (Spengler \& Callegari 2010, Spengler 2017). Se ubica a $28^{\circ} 51^{\prime} 49,8^{\prime \prime}$ latitud sur y $68^{\circ} 10^{\prime} 55,0^{\prime \prime}$ longitud oeste, sobre un barrial con abundante material lítico y cerámico en superficie. Es de destacar que este sitio se emplaza en las inmediaciones de un asentamiento tardío con presencia de cerámica de estilo Sanagasta e influencias de ocupación incaica (Spengler 2017). El análisis de la alfarería recolectada $(\mathrm{N}=167)$ permitió identificar fragmentos Ordinarios (35,92\%), Inclusiones Finas (28,14\%), Aguada (18,56\%) y Sanagasta (17,37\%). Atendiendo a las características de la muestra cerámica y al excelente estado de conservación de la estructura de Rueda de Piedra, consideramos que 


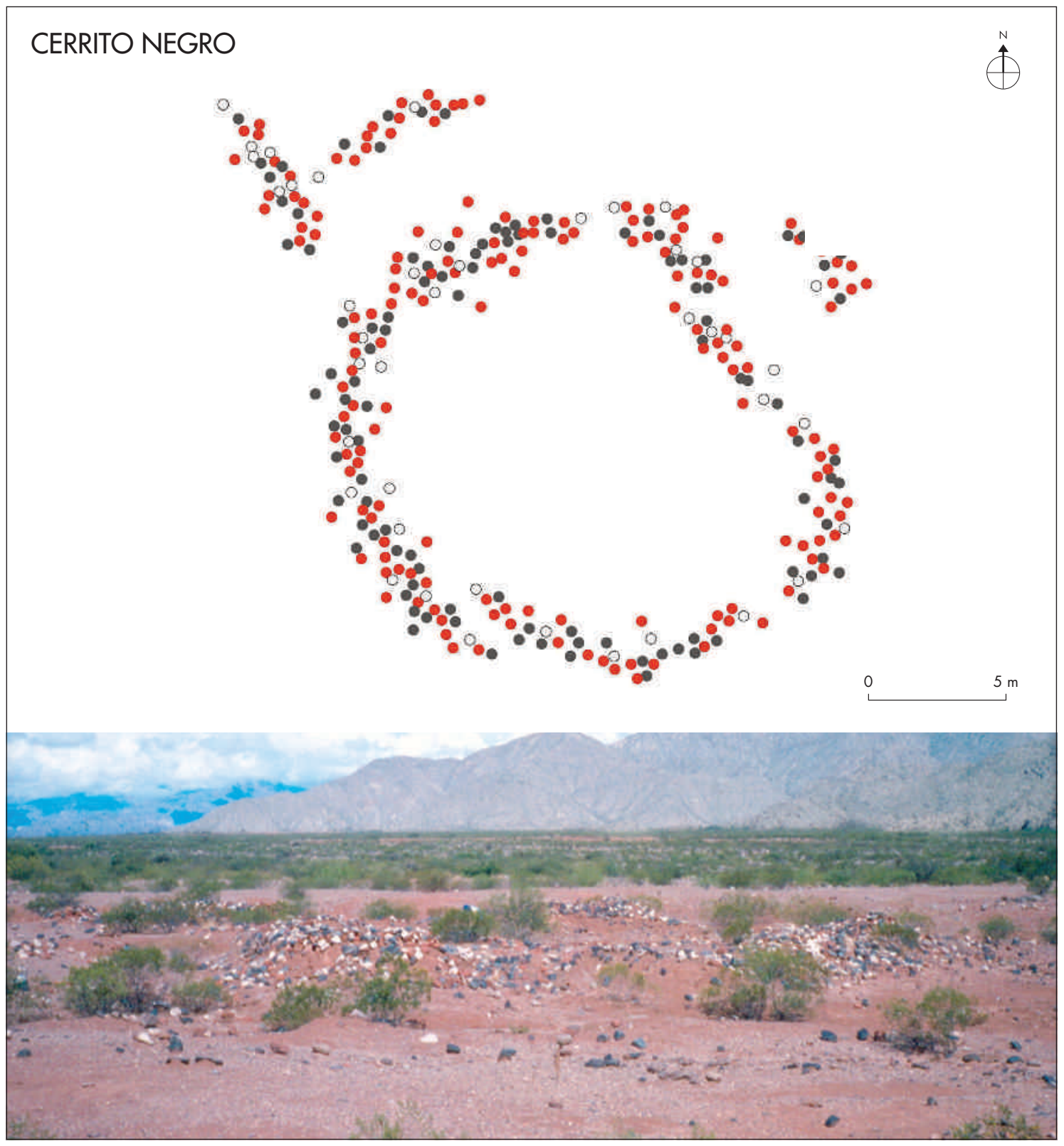

Figura 13. Plano y fotografía de la estructura de Cerrito Negro. Figure 13. Plan and photo of the Cerrito Negro structure.

el uso de este espacio podría haberse prolongado en el tiempo hasta momentos tardíos.

El soporte de este geoglifo consiste en un terraplén de tierra que fue cubierto por rocas de colores (fig. 9). Esta estructura se distingue de las anteriores pues el soporte de base presenta una morfología subcircular que se continúa en un amplio pasillo cuyo acceso se orienta hacia el este y conduce a su interior. En las inmediaciones se observa una serie de pequeños muros concéntricos, consistentes en elevaciones de tierra cubiertas por piedras de colores. El conjunto presenta un diámetro interior de $11 \mathrm{~m}$ y aproximadamente 35 $\mathrm{m}$ de largo y $30 \mathrm{~m}$ de ancho máximo. Aún es posible visualizar de manera relativamente clara los picos que conforman el diseño de estrella a través de la alternancia en el uso de las tonalidades de las piedras. 


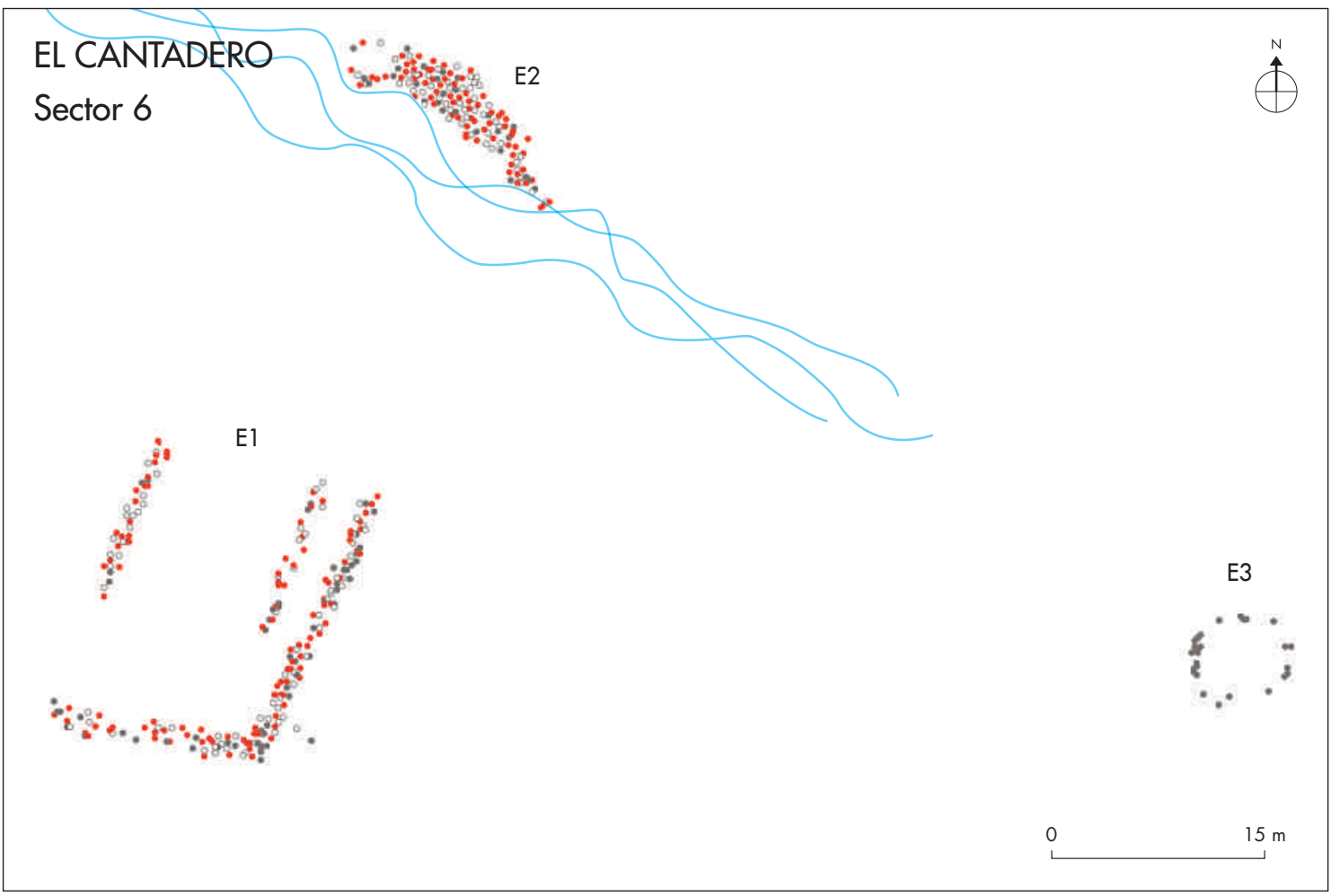

Figura 14. Plano de las estructuras del sector 6 de El Cantadero. Figure 14. Plan of the structures in sector 6 of El Cantadero.

\section{VALLE DE ANTINACO}

Sobre la vertiente oriental de la sierra de Famatina se registraron cuatro localidades con presencia de geoglifos, emplazadas en valles y quebradas subsidiarias al amplio Valle de Antinaco.

\section{Angulos}

Sobre las barrancas del río Durazno y aproximadamente a 1,5 km de la actual localidad de Angulos se identificó un geoglifo con diseño de estrella (fig. 10), ubicado a $28^{\circ} 39^{\prime} 29,5^{\prime \prime}$ latitud sur y $67^{\circ} 37^{\prime} 37,5^{\prime \prime}$ longitud oeste. En un informe sobre los sitios de la zona, De la Fuente y Quiroga (1980) ya habían mencionado la presencia de una estructura muy similar a las estrellas de Vinchina. La misma presenta un diámetro exterior de aproximadamente $15 \mathrm{~m}$, uno interior de $9 \mathrm{~m}$ y se encuentra ubicada frente a una pequeña plataforma, similar a las registradas en los espacios semipúblicos de La Cuestecilla y sus aldeas circundantes (Callegari et al. 2013). En las inmediaciones también se identificaron algunos recintos y cantidad de campos de cultivo. Se realizó una recolección de material cerámico de superficie $(\mathrm{N}=34)$, cuyo análisis permitió identificar fragmentos Aguada (55,88\%), Inclusiones Finas (20,59\%), Allpatauca (14,71\%) y Ordinarios $(8,82 \%)$.

\section{La Cuestecilla}

El sitio La Cuestecilla (LC) está ubicado en el fondo del Valle de Antinaco, entre las actuales localidades de Pituil y Chañarmuyo. Se trata de un asentamiento Aguada de grandes dimensiones compuesto por conjuntos residenciales rodeados de amplios espacios de cultivo. Según la secuencia de fechados $\mathrm{C}^{14}$ obtenidos, este sitio parece haber tenido una larga ocupación entre ca. 100 AC y 1250 AD (Callegari et al. 2013). Los materiales cerámicos recuperados de diferentes unidades de recolección y excavación corroboran estos resultados (Gonaldi et al. 2008, Callegari et al. 2013). Es entre los espacios productivos donde se observó la presencia de tres estructuras de piedras de colores (LC E1, LC E2 y LC E3). 
LC E1: Esta estructura se emplaza a $28^{\circ} 36^{\prime} 00,3^{\prime \prime}$ latitud sur y $67^{\circ} 32^{\prime} 55,9^{\prime \prime}$ longitud oeste. Consiste en tres alineamientos subparalelos de tierra, cuyos largos oscilan entre 6 y $15 \mathrm{~m}$, cubiertos por piedras de colores (fig. 11). El material colectado en superficie $(\mathrm{N}=276)$ fue identificado como Ordinarios (40,94\%), Aguada (28,99\%), Inclusiones Finas (22,83\%), Allpatauca (3,98\%), Ciénaga $(1,09 \%)$ e indeterminados $(2,17 \%)$.

LC E2: Se trata de una estructura de piedras de colores ubicada a $28^{\circ} 35^{\prime} 58,7^{\prime \prime}$ latitud sur y $67^{\circ} 32^{\prime} 55,4^{\prime \prime}$ longitud oeste. A pesar de estar afectada por los agentes erosivos se pudo observar que está conformada por dos semicírculos concéntricos que se abren en dirección sudoeste, cuyos diámetros oscilan entre los $14 \mathrm{~m}$ y los $9 \mathrm{~m}$ (fig. 12). El material cerámico colectado en superficie $(\mathrm{N}=39)$ fue identificado como Aguada (51,28\%), Ordinarios (23,08\%), Sanagasta (15,38\%), Inclusiones Finas $(7,69 \%)$ e indeterminados $(2,56 \%)$.

LC E3: Los vestigios de esta estructura se ubican a $28^{\circ}$ $35^{\prime} 21,9^{\prime \prime}$ latitud sur y $67^{\circ} 31^{\prime} 05,6^{\prime \prime}$ longitud oeste, entre los campos de cultivo y posibles corrales que rodean el sitio La Cuestecilla. Lamentablemente, una torrentera la seccionó en su parte me dia provocando que cantidad de las piedras que la constituían se deslizaran hacia el interior de esta, imposibilitando reconstruir su forma y dimensiones originales; no obstante, es evidente que tuvo grandes proporciones. En este caso, los estilos cerámicos identificados $(\mathrm{N}=150)$ son Aguada (33\%), Inclusiones Finas (27\%), Ordinarios (26\%), Allpatauca (8\%), Sanagasta (3\%), Ciénaga (1\%), Saujil (1\%) e indeterminados (1\%).

\section{Cerrito Negro}

En las inmediaciones de la localidad de Pituil, dentro de la finca Cerrito Negro, se identificó una gran estructura de piedras de colores, emplazada a $28^{\circ} 35^{\prime} 45,5^{\prime \prime}$ latitud sur y $67^{\circ} 31^{\prime} 25,11^{\prime \prime}$ longitud oeste. La misma presenta una planta subcircular con dimensiones que oscilan entre los $24 \mathrm{~m}$ de largo y los $17 \mathrm{~m}$ de ancho (fig. 13). Se encuentra conformada por muros confeccionados mediante tierra apisonada y cubiertos luego con piedras de colores, cuyas alturas varían entre 0,20 y $1 \mathrm{~m}$. En algunos tramos, la estructura parece presentar muros concéntricos y lineales de menores dimensiones que circundan la construcción principal (Callegari \& Raviña
2000). Dado que en la actualidad se encuentra dentro de una finca y rodeada por viñedos, no fue posible recuperar ningún tipo de registro arqueológico. No obstante, en las inmediaciones se han individualizado construcciones agrícolas prehispánicas.

\section{El Cantadero}

Esta localidad se encuentra dentro de la finca El Cantadero, con una ubicación de $28^{\circ} 35^{\prime} 36,5^{\prime \prime}$ latitud sur y $67^{\circ} 31^{\prime} 09,4^{\prime \prime}$ longitud oeste, aproximadamente a 2,5 km de Cerrito Negro. Ha sido fuertemente impactada por los agentes erosivos que originaron un amplio barrial sobre cuya superficie actualmente se observan concentraciones de material arqueológico y alineamientos de rocas que parecieran haber formado parte de cimientos de viviendas (Raviña 1986, Raviña \& Callegari 1988, Callegari \& Raviña 2000). Los trabajos realizados por Raviña y Callegari (1988) registraron dos sectores con construcciones de piedras de colores, denominados 6 y 7 .

En el sector 6 se identificaron tres estructuras (E1, E2 y E3) que fueron relevadas en su totalidad (fig. 14). E1 muestra una planta relativamente rectangular, de 20 $\mathrm{m}$ de largo y $16 \mathrm{~m}$ de ancho, conformada por muros de $1 \mathrm{~m}$ de espesor y $0,20 \mathrm{~m}$ de altura. Consiste en cuatro hiladas de tierra cubiertas por piedras de colores, tres de las cuales se disponen de forma subparalela siguiendo una dirección aproximada noreste-sudoeste. A $30 \mathrm{~m}$ con dirección noreste se ubica E2, que consiste en un montículo de tierra de aproximadamente $0,60 \mathrm{~m}$ de altura. El mismo fue cubierto con piedras de colores y se encuentra muy deteriorado pues fue atravesado por una torrentera. Por su parte, E3 corresponde a una pequeña estructura circular de piedras grises relativamente sobreelevada de aproximadamente $6 \mathrm{~m}$ de diámetro. En las inmediaciones también se identificaron algunos recintos de planta subcircular muy afectados por la acción de los agentes erosivos. El análisis del material cerámico colectado en este sector $(\mathrm{N}=147)$ mostró los siguientes estilos: Aguada (56,47\%), Inclusiones Finas $(21,76 \%)$, Ciénaga (10,88\%), Ordinarios $(9,52 \%)$ y Sanagasta (1,36\%) (Raviña 1986, Raviña \& Callegari 1988, Callegari \& Raviña 2000).

El sector 7 de El Cantadero se ubica a $400 \mathrm{~m}$ al oeste del conjunto mencionado. Allí se registraron 6 estructuras totalmente cubiertas con piedras multicolores. En primer lugar, se individualizó un montículo 
Tabla 1. íntesis de las principales características de las estructuras de piedras de colores. Table 1. Summary of the main features of the colored stone structures.

\begin{tabular}{|c|c|c|c|c|c|c|c|}
\hline $\begin{array}{c}\text { SITIO - } \\
\text { ESTRUCTURA }\end{array}$ & UBICACIÓN & $\begin{array}{c}\text { TÉCNICA } \\
\text { CONSTRUCTIVA }\end{array}$ & DISEÑO & DIMENSIONES & $\begin{array}{l}\text { COLORES } \\
\text { DE LAS } \\
\text { PIEDRAS }\end{array}$ & $\begin{array}{l}\text { MATERIAL } \\
\text { CERÁMICO } \\
\text { DIAGNÓSTICO } \\
\text { ASOCIADO }\end{array}$ & $\begin{array}{l}\text { CRONOLOGÍA } \\
\text { RELATIVA Y } \\
\text { ABSOLUTA }\end{array}$ \\
\hline $\begin{array}{l}\text { Estrellas de } \\
\text { Vinchina E1 }\end{array}$ & $\begin{array}{l}\text { Valle de } \\
\text { Vinchina }\end{array}$ & $\begin{array}{c}\text { Aditiva s/ } \\
\text { terraplenado }\end{array}$ & Estrella & $\begin{array}{l}\varnothing \mathrm{E}: 26 \mathrm{~m} \\
\varnothing \mathrm{I}: 11 \mathrm{~m} \\
\mathrm{H}: 0,50 \mathrm{~m}\end{array}$ & $\begin{array}{l}\text { Rojo, negro } \\
\text { y blanco }\end{array}$ & $\begin{array}{l}\text { Ciénaga, } \\
\text { Aguada y } \\
\text { Sanagasta }\end{array}$ & $\begin{array}{l}\text { P. Temprano, } \\
\text { Medio y } \\
\text { Tardío }\end{array}$ \\
\hline $\begin{array}{c}\text { Estrellas de } \\
\text { Vinchina E2 }\end{array}$ & $\begin{array}{c}\text { Valle de } \\
\text { Vinchina }\end{array}$ & $\begin{array}{l}\text { Aditiva s/ } \\
\text { terraplenado }\end{array}$ & Estrella & $\begin{array}{c}\varnothing \mathrm{E}: 15 \mathrm{~m} \\
\varnothing \mathrm{I}: 4 \mathrm{~m}\end{array}$ & $\begin{array}{l}\text { Rojo, negro } \\
\text { y blanco }\end{array}$ & $\begin{array}{l}\text { Aguada y } \\
\text { Sanagasta }\end{array}$ & $\begin{array}{l}\text { P. Medio } \\
\text { y Tardío }\end{array}$ \\
\hline $\begin{array}{c}\text { Estrellas de } \\
\text { Vinchina E3- } \\
\text { E4-E6-E7 }\end{array}$ & $\begin{array}{l}\text { Valle de } \\
\text { Vinchina }\end{array}$ & $\begin{array}{c}\text { Aditiva s/ } \\
\text { terraplenado }\end{array}$ & Estrella & - & $\begin{array}{l}\text { Rojo, negro } \\
\text { y blanco }\end{array}$ & $\begin{array}{l}\text { Aguada y } \\
\text { Sanagasta }\end{array}$ & $\begin{array}{l}\text { P. Medio } \\
\text { y Tardío }\end{array}$ \\
\hline $\begin{array}{c}\text { Estrellas de } \\
\text { Vinchina E5 }\end{array}$ & $\begin{array}{c}\text { Valle de } \\
\text { Vinchina }\end{array}$ & $\begin{array}{l}\text { Aditiva s/ } \\
\text { terraplenado }\end{array}$ & Estrella & - & $\begin{array}{c}\text { Negro } \\
\text { y blanco }\end{array}$ & $\begin{array}{l}\text { Aguada y } \\
\text { Sanagasta }\end{array}$ & $\begin{array}{l}\text { P. Medio } \\
\text { y Tardío }\end{array}$ \\
\hline $\begin{array}{l}\text { Las Eras } \\
\text { Viejas } 2\end{array}$ & $\begin{array}{l}\text { Valle de } \\
\text { Vinchina }\end{array}$ & $\begin{array}{c}\text { Aditiva s/ } \\
\text { terraplenado }\end{array}$ & Estrella (?) & $\varnothing 11 \mathrm{~m}$ & $\begin{array}{l}\text { Rojo, negro } \\
\text { y blanco }\end{array}$ & $\begin{array}{l}\text { Aguada y } \\
\text { Sanagasta }\end{array}$ & $\begin{array}{l}\text { P. Medio } \\
\text { y Tardío }\end{array}$ \\
\hline $\begin{array}{l}\text { Las Eras } \\
\text { Viejas } 3\end{array}$ & $\begin{array}{l}\text { Valle de } \\
\text { Vinchina }\end{array}$ & $\begin{array}{l}\text { Aditiva s/ } \\
\text { terraplenado }\end{array}$ & Estrella & $\varnothing 10 / 11 \mathrm{~m}$ & $\begin{array}{l}\text { Rojo, negro } \\
\text { y blanco }\end{array}$ & $\begin{array}{l}\text { Aguada y } \\
\text { Sanagasta }\end{array}$ & $\begin{array}{l}\text { P. Temprano, } \\
\text { Medio y } \\
\text { Tardío } \\
\text { F. C14 LP } \\
\text { 2793: } 2060 \pm \\
\text { 80 AP (cal. } 1 \\
\text { sig. } 112 \mathrm{AC} \mathrm{-} \\
80 \mathrm{AD})\end{array}$ \\
\hline $\begin{array}{l}\text { Las Eras } \\
\text { Viejas } 4\end{array}$ & $\begin{array}{l}\text { Valle de } \\
\text { Vinchina }\end{array}$ & $\begin{array}{c}\text { Aditiva s/ } \\
\text { terraplenado }\end{array}$ & Estrella (?) & $\varnothing 10 \mathrm{~m}$ & $\begin{array}{l}\text { Rojo, negro } \\
\text { y blanco }\end{array}$ & Aguada & P. Medio \\
\hline $\begin{array}{c}\text { Las Eras Viejas } \\
18-\mathrm{E} 1\end{array}$ & $\begin{array}{l}\text { Valle de } \\
\text { Vinchina }\end{array}$ & $\begin{array}{c}\text { Aditiva s/ } \\
\text { terraplenado }\end{array}$ & Estrella & $\varnothing 10 / 11 \mathrm{~m}$ & $\begin{array}{l}\text { Rojo, negro } \\
\text { y blanco }\end{array}$ & $\begin{array}{l}\text { Aguada y } \\
\text { Sanagasta }\end{array}$ & $\begin{array}{l}\text { P. Medio } \\
\text { y Tardío }\end{array}$ \\
\hline $\begin{array}{c}\text { Las Eras Viejas } \\
18-\mathrm{E} 2\end{array}$ & $\begin{array}{l}\text { Valle de } \\
\text { Vinchina }\end{array}$ & $\begin{array}{l}\text { Aditiva s/ } \\
\text { terraplenado }\end{array}$ & Estrella & $\varnothing 10 / 11 \mathrm{~m}$ & $\begin{array}{l}\text { Rojo, negro } \\
\text { y blanco }\end{array}$ & $\begin{array}{l}\text { Aguada y } \\
\text { Sanagasta }\end{array}$ & $\begin{array}{l}\text { P. Medio } \\
\text { y Tardío }\end{array}$ \\
\hline $\begin{array}{c}\text { Las Eras Viejas } \\
18-\mathrm{E} 4\end{array}$ & $\begin{array}{l}\text { Valle de } \\
\text { Vinchina }\end{array}$ & $\begin{array}{c}\text { Aditiva s/ } \\
\text { terraplenado }\end{array}$ & Espiralado & $\varnothing 10 \mathrm{~m}$ & $\begin{array}{l}\text { Rojo, negro } \\
\text { y blanco }\end{array}$ & $\begin{array}{l}\text { Aguada y } \\
\text { Sanagasta }\end{array}$ & $\begin{array}{l}\text { P. Temprano, } \\
\text { Medio y } \\
\text { Tardío } \\
\text { F. C14 LP } \\
\text { 2814: } 2060 \pm \\
80 \text { AP (cal. } 1 \\
\text { sig. } 316 \text { AD. - } \\
415 \text { AD) }\end{array}$ \\
\hline $\begin{array}{c}\text { Las Eras Viejas } \\
18-\text { E5 }\end{array}$ & $\begin{array}{l}\text { Valle de } \\
\text { Vinchina }\end{array}$ & Aditiva & Indet. & $\varnothing 11 / 6 \mathrm{~m}$ & $\begin{array}{l}\text { Rojo, negro } \\
\text { y blanco }\end{array}$ & $\begin{array}{l}\text { Aguada y } \\
\text { Sanagasta }\end{array}$ & $\begin{array}{l}\text { P. Medio } \\
\text { y Tardío }\end{array}$ \\
\hline $\begin{array}{c}\text { Las Eras Viejas } \\
19\end{array}$ & $\begin{array}{l}\text { Valle de } \\
\text { Vinchina }\end{array}$ & $\begin{array}{c}\text { Aditiva s/ } \\
\text { terraplenado }\end{array}$ & Indet. & $\varnothing 10 \mathrm{~m}$ & $\begin{array}{l}\text { Rojo, negro } \\
\text { y blanco }\end{array}$ & Aguada & P. Medio \\
\hline $\begin{array}{l}\text { Rueda de } \\
\text { Piedra }\end{array}$ & $\begin{array}{l}\text { Valle de } \\
\text { Vinchina }\end{array}$ & $\begin{array}{l}\text { Aditiva s/ } \\
\text { terraplenado }\end{array}$ & Estrella & $\begin{array}{l}\varnothing \mathrm{I}: 11 \mathrm{~m} \\
\mathrm{~L}: 35 \mathrm{~m} \\
\text { A: } 30 \mathrm{~m}\end{array}$ & $\begin{array}{l}\text { Rojo, negro } \\
\text { y blanco }\end{array}$ & $\begin{array}{l}\text { Aguada y } \\
\text { Sanagasta }\end{array}$ & $\begin{array}{l}\text { P. Medio } \\
\text { y Tardío }\end{array}$ \\
\hline
\end{tabular}




\begin{tabular}{|c|c|c|c|c|c|c|c|}
\hline $\begin{array}{c}\text { SITIO - } \\
\text { ESTRUCTURA }\end{array}$ & UBICACIÓN & $\begin{array}{c}\text { TÉCNICA } \\
\text { CONSTRUCTIVA }\end{array}$ & DISEÑO & DIMENSIONES & $\begin{array}{l}\text { COLORES } \\
\text { DE LAS } \\
\text { PIEDRAS }\end{array}$ & $\begin{array}{c}\text { MATERIAL } \\
\text { CERÁMICO } \\
\text { DIAGNÓSTICO } \\
\text { ASOCIADO }\end{array}$ & $\begin{array}{l}\text { CRONOLOGÍA } \\
\text { RELATIVA Y } \\
\text { ABSOLUTA }\end{array}$ \\
\hline Angulos & $\begin{array}{l}\text { Valle de } \\
\text { Antinaco }\end{array}$ & $\begin{array}{c}\text { Aditiva s / } \\
\text { terraplenado }\end{array}$ & Estrella & $\begin{array}{c}\varnothing \mathrm{E}: 15 \mathrm{~m} \\
\varnothing \mathrm{I}: 9 \mathrm{~m}\end{array}$ & $\begin{array}{c}\text { Rojo, negro } \\
\text { y blanco }\end{array}$ & Aguada & P. Medio \\
\hline $\begin{array}{c}\text { La Cuestecilla } \\
\text { E1 }\end{array}$ & $\begin{array}{l}\text { Valle de } \\
\text { Antinaco }\end{array}$ & $\begin{array}{l}\text { Aditiva s/ } \\
\text { hiladas de } \\
\text { tierra }\end{array}$ & $\begin{array}{c}\text { Líneas } \\
\text { subparalelas }\end{array}$ & L: 6 a $15 \mathrm{~m}$ & $\begin{array}{l}\text { Rojo, negro } \\
\text { y blanco }\end{array}$ & $\begin{array}{c}\text { Ciénaga y } \\
\text { Aguada }\end{array}$ & $\begin{array}{l}\text { P. Temprano } \\
\text { y Medio }\end{array}$ \\
\hline $\begin{array}{c}\text { La Cuestecilla } \\
\text { E2 }\end{array}$ & $\begin{array}{l}\text { Valle de } \\
\text { Antinaco }\end{array}$ & $\begin{array}{l}\text { Aditiva s/ } \\
\text { hiladas de } \\
\text { tierra }\end{array}$ & $\begin{array}{c}\text { Líneas } \\
\text { concéntricas }\end{array}$ & $\varnothing 14 / 9 \mathrm{~m}$ & $\begin{array}{c}\text { Rojo, negro } \\
\text { y blanco }\end{array}$ & $\begin{array}{l}\text { Aguada y } \\
\text { Sanagasta }\end{array}$ & $\begin{array}{l}\text { P. Medio } \\
\text { y Tardío }\end{array}$ \\
\hline $\begin{array}{c}\text { La Cuestecilla } \\
\text { E3 }\end{array}$ & $\begin{array}{l}\text { Valle de } \\
\text { Antinaco }\end{array}$ & Aditiva/? & Indet. & Indet. & $\begin{array}{c}\text { Rojo, negro } \\
\text { y blanco }\end{array}$ & $\begin{array}{l}\text { Saujil, } \\
\text { Ciénaga, } \\
\text { Aguada y } \\
\text { Sanagasta }\end{array}$ & $\begin{array}{l}\text { P. Temprano, } \\
\text { Medio y } \\
\text { Tardío }\end{array}$ \\
\hline Cerrito Negro & $\begin{array}{l}\text { Valle de } \\
\text { Antinaco }\end{array}$ & $\begin{array}{c}\text { Aditiva s/ } \\
\text { muros de } \\
\text { tierra }\end{array}$ & Subcircular & $\begin{array}{c}\mathrm{L}: 24 \mathrm{~m} \\
\text { A:17 m } \\
\mathrm{H}: 0,2 / 1 \mathrm{~m}\end{array}$ & $\begin{array}{l}\text { Rojo, negro } \\
\text { y blanco }\end{array}$ & - & - \\
\hline $\begin{array}{c}\text { El Cantadero } \\
6-\mathrm{E} 1\end{array}$ & $\begin{array}{l}\text { Valle de } \\
\text { Antinaco }\end{array}$ & $\begin{array}{l}\text { Aditiva s/ } \\
\text { hiladas de } \\
\text { tierra }\end{array}$ & Subrectangular & $\begin{array}{l}\mathrm{L}: 20 \mathrm{~m} \\
\mathrm{~A}: 16 \mathrm{~m} \\
\mathrm{H}: 0,2 \mathrm{~m}\end{array}$ & $\begin{array}{c}\text { Rojo, negro } \\
\text { y blanco }\end{array}$ & $\begin{array}{l}\text { Ciénaga, } \\
\text { Aguada y } \\
\text { Sanagasta }\end{array}$ & $\begin{array}{l}\text { P. Temprano, } \\
\text { Medio } \\
\text { y Tardío }\end{array}$ \\
\hline $\begin{array}{c}\text { El Cantadero } \\
6-\mathrm{E} 2\end{array}$ & $\begin{array}{l}\text { Valle de } \\
\text { Antinaco }\end{array}$ & $\begin{array}{l}\text { Aditiva s / } \\
\text { montículo }\end{array}$ & Monticular & $\mathrm{H}: 0.60 \mathrm{~m}$ & $\begin{array}{c}\text { Rojo, negro } \\
\text { y blanco }\end{array}$ & $\begin{array}{l}\text { Ciénaga } \\
\text { Aguada y } \\
\text { Sanagasta }\end{array}$ & $\begin{array}{l}\text { P. Temprano, } \\
\text { Medio } \\
\text { y Tardío }\end{array}$ \\
\hline $\begin{array}{c}\text { El Cantadero } \\
7 \text { - E1 }\end{array}$ & $\begin{array}{l}\text { Valle de } \\
\text { Antinaco }\end{array}$ & $\begin{array}{l}\text { Aditiva s/ } \\
\text { montículo }\end{array}$ & Monticular & $\begin{array}{c}\varnothing 10 \mathrm{~m} \\
\mathrm{H}: 0,4 \mathrm{~m}\end{array}$ & $\begin{array}{c}\text { Rojo, negro } \\
\text { y blanco }\end{array}$ & $\begin{array}{l}\text { Ciénaga y } \\
\text { Aguada }\end{array}$ & $\begin{array}{l}\text { P. Temprano } \\
\text { y Medio }\end{array}$ \\
\hline $\begin{array}{l}\text { El Cantadero } \\
7 \text { - E2-E3-E4- } \\
\text { E5-E6 }\end{array}$ & $\begin{array}{l}\text { Valle de } \\
\text { Antinaco }\end{array}$ & $\begin{array}{c}\text { Aditiva s/ } \\
\text { muros de } \\
\text { tierra }\end{array}$ & Indet. & $\begin{array}{c}\varnothing 7 / 12 \mathrm{~m} \\
\mathrm{H}: 0,2 / 0,7 \mathrm{~m}\end{array}$ & $\begin{array}{c}\text { Rojo, negro } \\
\text { y blanco }\end{array}$ & $\begin{array}{l}\text { Ciénaga y } \\
\text { Aguada }\end{array}$ & $\begin{array}{l}\text { P. Temprano } \\
\text { y Medio }\end{array}$ \\
\hline
\end{tabular}

circular de $10 \mathrm{~m}$ de diámetro y $0,40 \mathrm{~m}$ de altura. Las 5 estructuras restantes están conformadas por muros de tierra con alturas de $0,20 \mathrm{~m}$ a $0,70 \mathrm{~m}$, que parecen haber formado grandes recintos con diámetros que oscilan entre 7 y $12 \mathrm{~m}$. Atendiendo a sus características formales y técnicas, estas construcciones serían muy similares a la estructura descrita para Cerrito Negro. El material cerámico recolectado en superficie $(\mathrm{N}=155)$ fue clasificado como Aguada (65,13\%), Ordinarios (20\%), Allpatauca (6,45\%), Ciénaga (5,16\%) e Inclusiones Finas (3,26\%) (Raviña 1986, Raviña \& Callegari 1988, Callegari \& Raviña 2000). Finalmente, en la tabla 1 se presenta una síntesis de la información desarrollada a lo largo de este acápite.

\section{CLASIFICACIÓN DE LOS DISTINTOS TIPOS DE ESTRUCTURAS}

A partir del análisis comparativo de las diferentes estructuras de piedras de colores observadas en el norte riojano, estas manifestaciones han sido clasificadas en cuatro tipos característicos:

Terraplenes circulares con la parte superior central algo deprimida, en los que tanto el talud como la circunferencia superior han sido cubiertos con piedras seleccionadas de color blanco, rojizo y negro/azulado, configurando por su alternancia diseños de estrella (fig. 15). Este tipo de estructuras suelen presentar uno o dos accesos al interior logrados por la ausencia de piedras. Los ejemplos más claros de estas construcciones son 

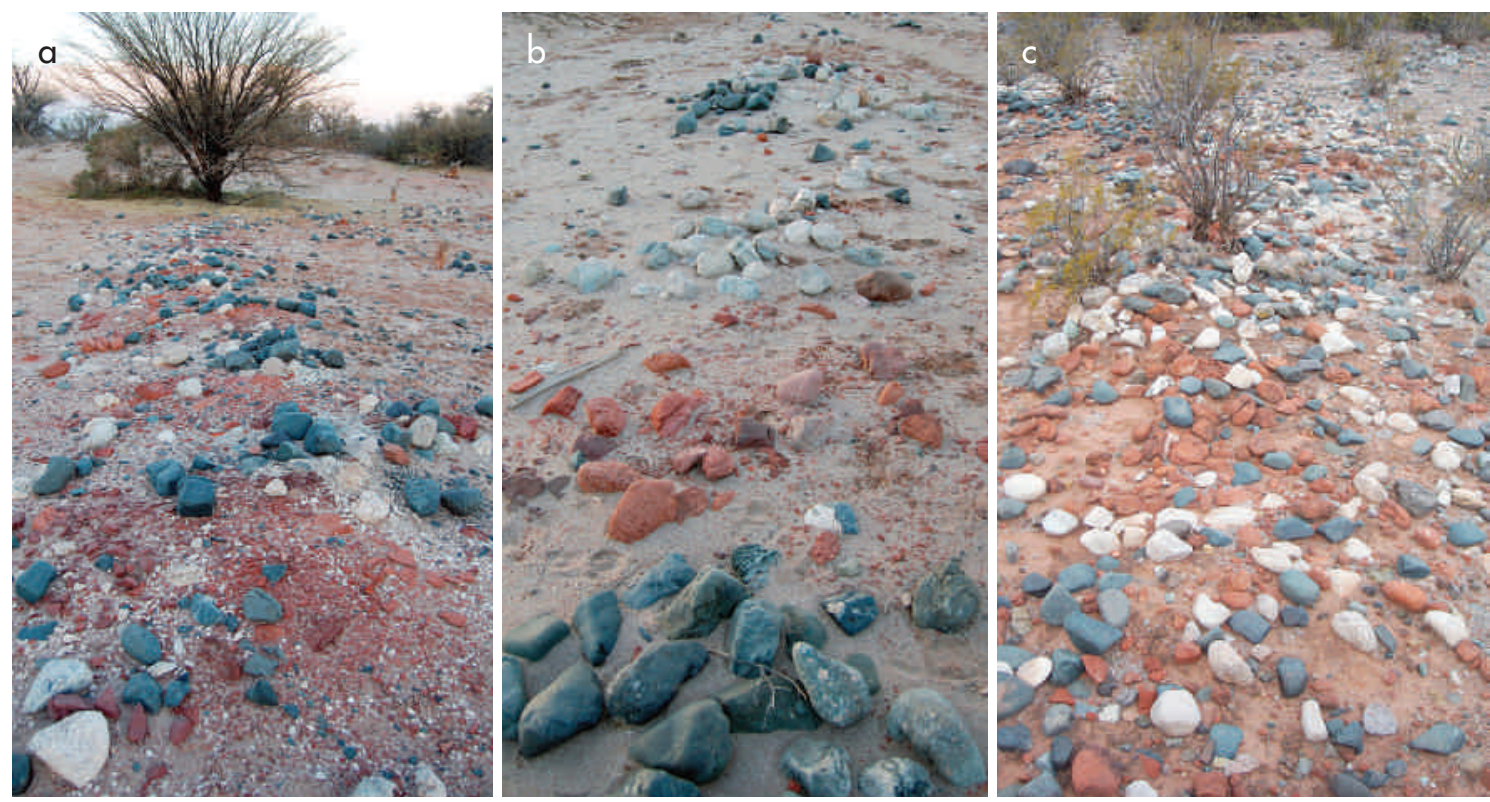

Figura 15. Detalle de la alternancia en el uso de los colores para la configuración de diseños en estrella: a-b) rueda de Piedra y c) ángulos. Figure 15. Detail of the alternating use of colors to create star-shaped designs: $\boldsymbol{a}$-b) wheel of Stone and $\boldsymbol{c}$ ) angles.

las Estrellas de Vinchina, EV2, EV3, EV18 (E1 y E2), Rueda de Piedra y Angulos.

Estructuras subcirculares conformadas por muros de tierra apisonada de entre 0,20 y $1 \mathrm{~m}$ de altura cubiertas por piedras de colores. De variados tamaños, delimitan amplios espacios a la manera de grandes recintos. Son ejemplos de este tipo de construcciones la descrita en Cerrito Negro y las 5 individualizadas en el sector 7 de El Cantadero.

Hileras de tierra rectas subparalelas y concéntricas de dimensiones variadas, cubiertas por piedras de colores. Son características de este grupo E1 y E2 de La Cuestecilla.

Montículos de tierra tapizados por piedras de colores. Este es el caso de E2 descrita para el sector 6 del sitio El Cantadero.

Es importante destacar que el rasgo compartido por los distintos tipos de estructuras, independientemente de sus características formales, es la selección de los mismos colores de piedras para su construcción. Este recurso produjo un fuerte impacto visual, que habría sido utilizado para connotar ciertos espacios cargados de significación.

Por otro lado, la gran mayoría de las estructuras circulares, tanto con diseños de estrellas como con líneas concéntricas, muestran diámetros que suelen oscilar entre los $10 \mathrm{~m}$ y los $11 \mathrm{~m}$. Por último, de las 29 construcciones registradas, solamente en 13 casos fue posible identificar la presencia de accesos, aunque sin mostrar recurrencias significativas en el patrón de orientación.

\section{CONSIDERACIONES FINALES}

De acuerdo con las evidencias cronológicas absolutas ${ }^{2} y$ relativas analizadas, podemos decir que estas expresiones visuales formaron parte de una prolongada tradición cultural precolombina, cuyas raíces se hunden en los inicios de la era o incluso un poco antes. Por otra parte, entre el material cerámico recuperado sobre la superficie de algunas de estas estructuras y sus alrededores se registró la presencia de fragmentos correspondientes al estilo Sanagasta, hecho que nos permite inferir que esta tradición habría continuado vigente, con variaciones y resignificaciones, inclusive hasta el Período Tardío. Sin embargo, puesto que la mayor parte de estas manifestaciones se encuentra asociada a contextos con alfarería de estilo Aguada (ca. 600-1000 AD), inferimos que habría sido durante el Período Medio o de Integración Regional cuando alcanzaron mayor significación. 
El análisis de la morfología de las plantas de este tipo de estructuras permitió un acercamiento a la comprensión de la práctica social que en ellas se desarrolló. En relación con esto es interesante señalar que la mayoría de los geoglifos elaborados sobre soportes plásticos en terraplén muestran uno o dos accesos al sector central, lo cual indicaría que el ingreso a este fue un acto de importancia en el desarrollo del ritual. Otro hecho importante es que los sondeos realizados en las estructuras de Las Eras Viejas mostraron fragmentos de carbón, cenizas y tierra quemada lo que estaría indicando que se habrían realizado fogatas en su centro, práctica que podría haber formado parte de la performance del ritual actuado en estos lugares significantes.

Las estructuras de Las Eras Viejas con fechados $\mathrm{C}^{14}$ tempranos muestran accesos a su interior a través de simples aberturas. En cambio, el geoglifo Rueda de Piedra, vinculado a un posible uso prolongado hasta momentos tardíos, presenta un amplio y largo pasillo que lleva al interior de la estructura. Esta situación nos hace pensar en la posibilidad de prácticas en procesión que recorrieran este corredor hasta llegar al escenario en donde se habría desarrollado parte de la ceremonia. Es así que, en el transcurso de esta larga tradición de más de 1000 años, algunas rutinas en la actuación del ritual habrían ido cambiando, adquiriendo mayor relevancia el ingreso a las estructuras y, al mismo tiempo, prolongándose el recorrido hacia el sector central.

Asimismo, consideramos que todas las estructuras de piedras de colores o geoglifos parecen haber sido construidas para significar determinados espacios a través del impacto visual que produjo la combinación de colores contrastantes. Al respecto, llama la atención la proximidad a tres elementos relativamente recurrentes en el paisaje: los cursos de agua, los espacios productivos y las quebradas o pasos naturales. En el primer caso, es notoria la cercanía de la mayoría de este tipo de construcciones a cursos de agua de envergadura, tanto permanentes como estacionales (Callegari \& Raviña 2000). Esta situación se observa en las Estrellas de Vinchina, Las Eras Viejas (especialmente en el caso de EV2, EV4 y EV18) y Angulos, en donde la proximidad a los ríos es inferior a los $500 \mathrm{~m}$. Por otra parte, se ha observado que el emplazamiento de varios geoglifos se encuentra rodeado de vestigios prehispánicos de campos de cultivo y redes de irrigación, vinculados a asentamientos del Período Medio (v. g. Cerrito Negro, La Cuestecilla y El Cantadero) y, en menor medida, del Período Tardío ( $v$. g. EV18 y EV2) (Callegari \& Raviña 2000, Callegari et al. 2013, Spengler 2017).

Finalmente, en las Estrellas de Vinchina y en Angulos se ha observado que las estructuras de piedras de colores muestran cierta proximidad a quebradas o pasos naturales. Esta situación nos permitiría inferir que, en algunos casos, este tipo de manifestaciones podría estar señalando la dirección o la presencia de corredores de tránsito en el paisaje. De esta manera, el particular alineamiento de las Estrellas de Vinchina parece estar marcando el ingreso a la Quebrada de La Troya, que finalmente conduce al paso cordillerano que cruza a Chile (Callegari \& Raviña 2000). Por su parte, la estructura de Angulos se ubica muy próxima a la quebrada homónima, que comunica con el Valle de Antinaco y con los parajes en donde se localizan las estructuras de La Cuestecilla, El Cantadero y Cerrito Negro.

Más allá de las importantes similitudes identificadas entre las estructuras localizadas en los valles de Vinchina y Antinaco, también es posible mencionar algunas diferencias entre ambos. Es así que en el Valle de Vinchina la mayoría de estas manifestaciones parecen haber figurado diseños de estrellas. Por su parte, en el Valle de Antinaco se registró solamente una construcción de este tipo, mientras que el resto corresponde a estructuras subcirculares, líneas subparalelas y concéntricas, y montículos tapizados de piedras multicolores.

En ambos valles, el factor color parece haber jugado un rol relevante en la cosmovisión de estos pueblos y su uso fue fundamental en la demarcación y significación de determinados lugares vinculados a ciertas prácticas socio-rituales. A diferencia de la mayoría de geoglifos identificados en territorios transcordilleranos, emplazados sobre laderas de cerros o lomadas que favorecieron su visibilidad, las manifestaciones del noroeste riojano fueron plasmadas sobre terreno llano y en ambientes de fondo de valle. Sin embargo, el uso de los colores fue sin duda una estrategia deliberada utilizada para impactar en el paisaje y ser vistos a la distancia.

Más allá de que la percepción e interpretación de los colores se encuentren estrechamente ligadas al bagaje cultural y a las experiencias previas de quienes los perciben, es posible pensar que las tonalidades mencionadas reiteradamente se vinculen a la experiencia universal de lo orgánico. De hecho, en términos de Turner (1967) el rojo podría ser considerado símbolo universal de la sangre, el blanco de la leche materna y del semen, y el negro de las heces, sintetizando la 
experiencia psicobiológica y generando así un plus de emoción agregada al lugar.

En relación con estas consideraciones, la cercanía de algunas de estas construcciones con espacios de cultivo podría estar vinculada a ceremonias asociadas con la fertilidad de la tierra (Callegari \& Raviña 2000). En este sentido, varios estudios han dado cuenta de la significación y el poder de los colores, como así también de las restricciones de su uso en el mundo andino. En esta línea, Bovisio (1992, citado en Burucúa et al. 1999) hace referencia a crónicas y visitas de extirpadores de idolatrías que informaron sobre aquellos colores que formaban parte de las vestimentas rituales de huacas y sacerdotes, entre los que se mencionan el rojo, el blanco, el amarillo, el negro y el azul. Por su parte, Cereceda (1990) menciona que entre los pueblos aymaras existe una división semántica y simbólica entre los colores naturales sin teñir (relacionados con el pastoreo y la ropa de los niños) de aquellos teñidos derivados del arco iris (v. g. rojo, amarillo, azul, verde, etc.). Estos últimos estarían vinculados a la agricultura, los rituales y las ceremonias, marcando una identidad social. Además, cabe señalar que el empleo de los colores negro, rojo y blanco estuvo ampliamente extendido en la decoración cerámica del NOA, especialmente en la alfarería de estilo Aguada (Callegari \& Raviña 2000).

En cuanto a los diseños, como ya mencionamos, se figuraron estrellas como resultado de la alternancia en el uso de los colores. Este motivo se encuentra muy poco representado en la decoración cerámica apareciendo solo en unas pocas vasijas Aguada gris grabado. Por su parte, los diseños circulares fueron ampliamente representados en la alfarería de estilo Aguada, especialmente en sus variantes pintadas, y en el arte rupestre de la zona. Esta asociación también podría aplicarse a la representación de líneas subparalelas, que suelen observarse en la decoración de la cerámica Aguada pintada (Callegari \& Raviña 2000).

Finalmente, consideramos que la noción de identidad implica una relación de pertenencia con un patrimonio que se asume y utiliza como propio (Lumbreras 1989, Kaulicke 2003). Dado que los geoglifos y las construcciones de piedras de colores únicamente han sido registradas en el sector meridional del fenómeno Aguada, proponemos que su uso habría favorecido y fortalecido la construcción de una identidad Aguada meridional. Por su parte, la gran amplitud espacial en la que se encuentran distribuidas estas manifestaciones nos permite inferir que sus constructores compartieron un mismo ideario, tradiciones y códigos de comunicación. De esta manera, las características formales, los diseños y el uso reiterado de ciertos colores, entre otros atributos, parecen haber sido el producto de una idea o percepción compartida por las poblaciones precolombinas que habitaron el norte de la Provincia de La Rioja y habrían estado estrechamente vinculados a sus esquemas de pensamiento, concepción del espacio y códigos de uso. Además, este tipo de expresiones plástico-arquitectónicas habrían actuado como un recurso mnemotécnico entre aquellos individuos que formaron parte de un entramado social, compartieron una misma tradición y participaron de ciertas prácticas constituyéndose, de esta manera, en memorias materializadas.

\section{NOTAS}

${ }^{1}$ Corresponde a la estructura 4 de la publicación de De la Fuente (1973).

${ }^{2}$ Es importante aclarar que los dos fechados tempranos obtenidos por el método de $\mathrm{C}^{14}$ provienen de dos geoglifos ubicados en el amplio barrial de Las Eras Viejas, distantes entre sí por aproximadamente $1 \mathrm{~km}$, hecho que nos permitiría desestimar una posible contaminación. Por otro lado, puesto que ambas muestras fueron tomadas del terraplén, elevado artificialmente para actuar como soporte de estas expresiones visuales, descartamos la posibilidad de que correspondan a una ocupación anterior.

\section{REFERENCIAS}

Ávila, F. 2011. Arqueología polícroma. El uso y la elección del color en expresiones plásticas. Boletín del Museo Chileno de Arte Precolombino 16 (2): 89-99.

BARrett, J. C. 1999. The mithycal landscape of the British Iron Age. En Archaeologies of landscapes: contemporary perspectives, W. Ashmore \& B. Knapp, Eds., pp. 253-265. Malden: Blackwell.

BAsile, M. 2013. Las manifestaciones plásticas de la región de Fiambalá: cambios y continuidades entre los siglos v y xv. En Delineando prácticas de la gente del pasado: los procesos socio-históricos del oeste catamarqueño, N. Ratto, Ed., pp. 177-238. Buenos Aires: Sociedad Argentina de Antropología.

Bradley, R. 2002. The past in prehistoric societies. Nueva York: Routledge.

Briones, L. \& Chacama, J. 1987. Arte rupestre de Ariquilda: análisis descriptivo de un sitio con geoglifos y su vinculación con la prehistoria regional. Chungara 18: 15-66. 
Burucúa, J. E., Siracusano, G. \& Jáuregui, A. 1999. Colores en los Andes: sacralidades prehispánicas y cristianas. Estudios de Arte y Estética 50: 317-345. México: Universidad Nacional Autónoma de México.

Callegari, A., Gonaldi, M. E., Spengler, G. \& Aciar, M. E. 2013. Construcción del paisaje en el Valle de Antinaco, Departamento de Famatina, Provincia de La Rioja (ca. 0-1300 AD). En Tradición e identidad. Arqueología y espacialidad. Enfoques, métodos y aplicación, I. Gordillo \& J. M. Vaquer, Eds., pp. 303-344. Quito: Abya Yala.

Callegari, A. \& Raviña, G. 1982 Ms. Diario de campo. Campaña a Las Eras Viejas, sector septentrional del Valle de Vinchina.

Callegari, A. \& Raviña, G. 2000. Construcciones de piedras de colores. El empleo recurrente del negro, rojo y blanco. En Arte en las rocas. Arte rupestre, menhires, y piedras de colores en Argentina, M. Podestá \& M. De Hoyos, Eds., pp. 112-120. Buenos Aires: Sociedad Argentina de Antropología.

Callegari, A. \& Spengler, G. 2010 Ms. El arte de las estrellas. Trabajo presentado al v TAAS. Reunión Internacional de Teoría Arqueológica en América del Sur. Caracas: Universidad Central de Venezuela.

Cereceda, V. 1990. A partir de los colores de un pájaro... Boletín del Museo Chileno de Arte Precolombino 4: 57-104.

Clarkson, P. 1998. Archeological imaginings: contextualization of images. En Reader in archeological theory. Post-processual and cognitive approaches, D. S. Whitley, Ed., pp. 119-132. Nueva York: Routledge.

Clarkson, P. \& Briones, L. 2001. Geoglifos, senderos y etnoarqueología de caravanas en el desierto chileno. Boletín del Museo Chileno de Arte Precolombino 8: 35-45.

Criado Boado, F. 1999. Del terreno al espacio: planteamientos y perspectivas para la arqueología del paisaje. CAPA 6: 1-82. Santiago de Compostela: Grupo de Investigación de Arqueología del Paisaje, Universidad de Santiago de Compostela.

De LA Fuente, N. 1973. Informe arqueológico sobre el Valle de Vinchina, Pcia. de La Rioja. Revista del Instituto de Antropología IV: 95-127.

De la Fuente, N. \& Quiroga, M. A. 1980. Informe sobre la arqueología de Angulos, Departamento de Famatina. Provincia de La Rioja (R. A.). Publicaciones del Centro de Estudios de Regiones Secas 2 (1): 3-17. FIore, D. 2011. Materialidad visual y arqueología de la imagen. Perspectivas conceptuales y propuestas metodológicas desde el sur de Sudamérica. Boletín del Museo Chileno de Arte Precolombino 16 (2): 101-119.

Gonaldi, M. E., Callegari, A., Spengler, G., Aumont, S., Rodríguez, M. G. \& WisNieski, M. L. 2008. El patrimonio arqueológico del norte del Dto. de Famatina y otros temas generales de la Arqueología. Buenos Aires: Asociación de Amigos del Instituto Nacional de Antropología.

Guráieb, G., Podestá, M., Rolandi, D. \& Damiani, O. 2007. Estructuras prehispánicas de piedra del Parque Provincial
Ischigualasto y su área de amortiguación, Prov. de San Juan. En Actas del XVI Congreso Nacional de Arqueología Argentina, tomo III, pp. 529-535. San Salvador de Jujuy: Universidad Nacional de Jujuy.

Hosler, D. 1998. Sound, color and meaning in the metallurgy of ancient west Mexico. En Reader in archeological theory. Post-processual and cognitive approaches, D. Whitley, Ed., pp. 104-118. Nueva York: Routledge.

INGOLD, T. 1993. The temporality of landscape. World Archaeology 25 (2): 152-174.

INGOLD, T. 2000. The perception of the environment: essays of livelihood, dwelling and skill. Londres-Nueva York: Routledge.

KAULICKE, P. 2003. Memoria historiografiada y memoria materializada. Problemas en la percepción del pasado andino preeuropeo. Estudios Atacameños 26: 17-34.

López De Olivera, M. L. 2012. Interiorizando el diseño. San Miguel de Tucumán: Facultad de Arquitectura y Urbanismo, Universidad Nacional de Tucumán.

Lumbreras, L. 1989. La cuestión del patrimonio cultural en las condiciones pluriculturales de origen colonial: el caso del Perú. En Antropología y políticas culturales. Patrimonio e identidad, R. Ceballos \& N. García Canclini, Eds., pp. 53-64. Buenos Aires: Talleres Gráficos de la Dirección Nacional del Registro Oficial.

Mañana Borrazás, P., Blanco Rotea, R. \& Ayán Vila, X. 2002. Bases teórico-metodológicas para la arqueología de la arquitectura. TAPA 25. Santiago de Compostela: LPPP, Instituto de Investigacións Tecnolóxicas, Universidad de Santiago de Compostela.

Moore, J. 1996. Architecture and power in the ancient Andes. The archaeology of public buildings. Cambridge: Cambridge University Press.

Muscio, H. 2006. Una aproximación evolutiva a la complejidad y al orden social temprano a través del estudio de representaciones rupestres de la quebrada de Matancillas (puna argentina). Estudios Atacameños 31: 9-30.

NúÑEZ, L. 1976. Geoglifos y tráfico de caravanas en el desierto chileno. En Volumen Homenaje al Dr. G. Le Paige, H. Niemeyer, Ed., pp. 147-202. Antofagasta: Universidad del Norte.

NúÑEZ, L. 1985. Petroglifos y tráfico en el desierto chileno. En Estudios de arte rupestre, C. Aldunate, J. Berenguer \& V. Castro, Eds., pp. 243-264. Santiago: Museo Chileno de Arte Precolombino.

Potter, J. 2004. The creation of person, the creation of place: hunting landscapes in the American southwest. American Antiquity 69 (2): 322-338. Washington: Society for American Archaeology.

Prieto, R. 1992. Geoglifos del río Jáchal, provincia de San Juan. Publicaciones 19: 1-9. San Juan: Instituto de Investigaciones Arqueológicas y Museo.

RAFFINO, R. 1981. Sobre allpataucas y pirámides ceremoniales. Revista Novedades del Museo de La Plata 1 (1). 
Raffino, R., Raviña, G., Baldini, L. \& Iacona, A. 1982. La expansión septentrional de la cultura de La Aguada en el Noroeste Argentino. Cuadernos del Instituto Nacional de Antropología 9: 7-35.

RAviÑA, G. 1986. El Cantadero: un nuevo asentamiento Aguada en el noA. Revista Novedades del Museo de La Plata 1 (10).

RAVIÑA, G. \& CALlEgari, A. 1988. Hallazgos arqueológicos en El Cantadero (Famatina, La Rioja). Antropología 4: 10-17.

Spengler, G. 2017. Arquitectura y asentamiento de las sociedades del Período Tardío del sector centro-norte del Valle de Vinchina, La Rioja. Tesis doctoral, Facultad de Filosofía y Letras. Universidad de Buenos Aires.

Spengler, G. \& Callegari, A. 2010. Manifestaciones del Período Tardío (850 a 1480 DC) en el noroeste riojano.
En Arqueología del centro oeste argentino, R. Bárcena, Ed., pp. 233-252. Mendoza: Xama, Serie Monografías. INCIHUSA, CONICET.

Thomas, J. 2001. Archaeologies of place and landscape. En Archaeological theory today, I. Hodder, Ed., pp. 165-186. Cambridge: Cambridge University Press.

Tilley, C. 2008. Phenomenological approaches to landscapes archaeology. En Handbook of landscape archaeology, J. Thomas, Ed., pp. 271-276. California: Left Coast Press.

Turner, V. 1967. La selva de los símbolos. Madrid: Siglo XXI.

Valenzuela, D. \& Clarkson, P. 2014. Geoglyphs. En Encyclopedia of global archaeology, C. Smith, Ed., pp. 3017-3029. Nueva York: Springer. 